\title{
Salutogenic Approaches to Dementia Care
}

\author{
Jan A. Golembiewski and John Zeisel
}

\section{Introduction}

Salutogenesis is a theory of health focused on strengthening the forces that support life and engagement, rather than on preventing or treating disease. In doing so, salutogenesis propels a person's ontological sense of self (their sense of coherence - SOC) towards full engagement with life and away from infirmity and death. 'Good health' and 'a strong sense of coherence (SOC)' are thus powerfully correlated; helping people feel strong and resilient to life events, pathogens, and other challenges. This approach contrasts to health disciplines ('white-coat medicine') that seek to draw people back from physical and mental failure to the point where the pathogens and insults have been neutralised.

Salutogenesis theory is useful in developing ecopsychosocial (Zeisel et al., 2016), non-pharmacological aged and dementia care interventions because it incorporates not only factors that lead to infirmity but also ones that lead towards better health. Salutogenesis provides practical tools to understand and affect this passage, managing cognitive and other age-related declines by maximising all available resources. Unlike white-coat medicine, the focus is not on eliminating a disease (although this approach is still compatible); instead, salutogenesis improves resilience and a person's capacity to engage in life more completely, fortifying the ability to cope with the challenges that are a normal part of life's passage even the challenges associated with ageing and dementia (Fig. 48.1).

While salutogenic effects are generalisable, its tools specific resistance resources (SRRs) - can be quite specific.

J. A. Golembiewski $(\square)$

Psychological Design, Sydney, Australia

Interior Architecture and Environmental Design, Bilkent University, Ankara, Turkey

e-mail: jg@psychological.design

J. Zeisel

Hearthstone Institute and the I'm Still Here Foundation,

Winchester, MA, USA

e-mail: zeisel@thehearth.org
SRRs focus on supporting a person's endogenous adaptive capacity in three domains: intellectual (comprehensibility), physical (manageability) and affective (meaningfulness).

Salutogenic theory holds that while disease is unquestionably caused by pathogens, specific stressors, genetics, and so on, good health is not merely the absence of these things. In the face of life's challenges (including disease), health is maintained by a strong SOC, which in turn is drawn from the generalised composite of all resistance resources (the GRRs). A strong SOC is expressed as hope, optimism, and buoyancy in the face of adversity. When a person can no longer manage or even understand life's challenges, their SOC becomes depleted, the GRRs needed to maintain their vitality and reason to live are insufficient for the job, and disease and infirmity follow.

While salutogenic theory explains and predicts resilience in the face of assaults on body and mind, the question remains, 'How does a salutogenic framework explain resilience in the face of the natural and inevitable course of ageing - especially once cognitive, emotional, and physical decline has already set in?' And what about when a person faces the stressful inevitability of death (Butler, 1975)? With age, a salutogenic approach focuses on improving a person's SRRs to continually strengthening their SOC by targeting tailored interventions in each of the three person-centric salutogenic domains (comprehensibility, manageability and meaningfulness).

The advancement of SRRs is described more fully in Chap. 26 of this volume. In simple terms, anything that helps people with dementia manage corporeal challenges such as barrier-free access and physical comfort supports manageability. Manageability is naturally and increasingly under pressure as people age because of deteriorating vision and hearing, and because of losses in mobility due to arthritis, loss of bone density, muscle control and other somatic failures. Meaningfulness is the powerhouse SRR: meaningfulness gives people the reason to live, to push back against adversity and get through it all (Antonovsky, 1979). Meaningfulness is supported by qualities that Simone De 
Fig. 48.1 Quality of life over the lifetime. (Jan A. Golembiewski)

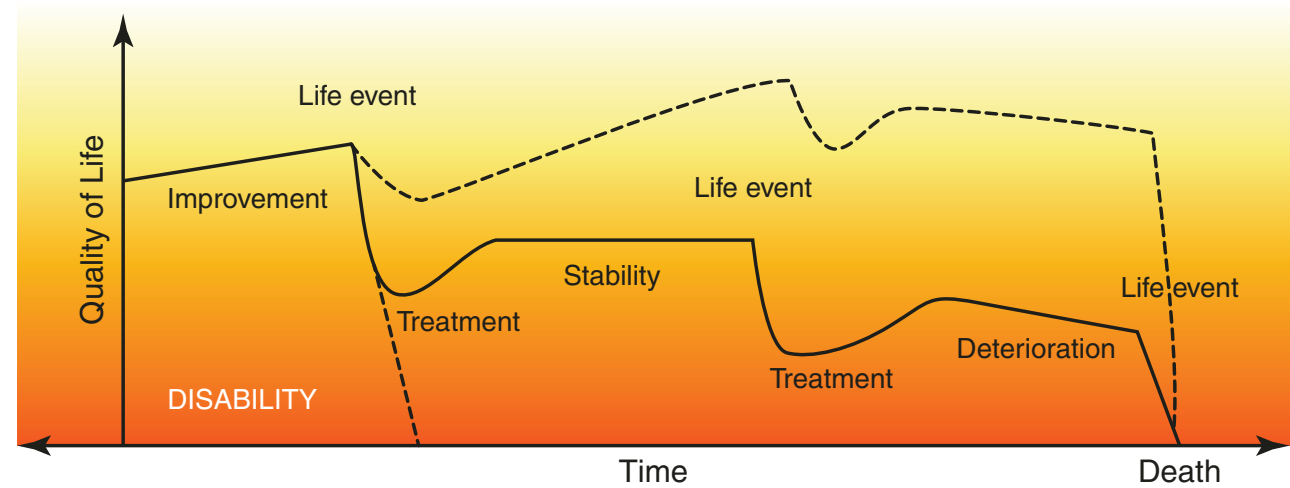

Beauvoir summarised beautifully; '(the) ends that give our existence meaning-devotion to individuals, to groups, or to causes-social, political, intellectual, or creative work... One's life has value so long as one attributes value to the lives of others, by means of love, friendship, indignation, compassion... It's better to live a committed life, even when all other illusions have vanished' (1972, p. 541).

Comprehensibility - the intellectual domain - is particularly challenged when people develop dementia. A great deal can be done to support comprehensibility and this chapter focuses on the subject. In simplest terms, comprehensibility interventions maintain a person's intellectual abilities as long as possible and, as these decline, build a comprehensibility framework in its place. Just as children live in trust before they develop the epistemic knowing they will need to survive when they become independent, so too can those with dementia: as epistemic memories become difficult to access, people living with dementia (PLWD) can employ hope, faith and simplicity to support their SOC.

Dementia challenges a salutogenic approach because the GRD headwinds grow stronger as people age and managing day-to-day living becomes physically more trying. People's sensitivity to the environment also becomes greater, especially when there are cognitive and memory losses. Furthermore, as one SRR is eroded (typically comprehensibility with dementia and manageability with ageing generally), the other SRRs are threatened. Take hearing, for instance. When a person becomes particularly hard of hearing, they do not merely lose the ability to hear: their ability to communicate with others diminishes - especially amongst other elderly people with similar losses, and to children who may not be able to compensate with writing and other visual cues. Unchecked, this leads to the distancing of friends and family, a key meaningfulness SRR. Given such circumstances, a person can easily give up. 'Why bother?' is a question that cuts at the heart of meaningfulness. Because salutogenic dynamics shift with age, this question does not change underlying salutogenic principles, it simply means the SRRs must be reinforced as they are required to work harder.

To get the balance right when dealing with advancing dementia, it is essential to identify and, as far as possible, remove environmental stressors - pathogens, social stressors, and anything else that directly burdens the natural salutogenic resources and counteracts salutogenic interventions. Such stressors include confusing building plans which affect comprehensibility and process-centred models of care (MOCs) that compromise a person's sense of meaningfulness. Salutogenic interventions must be more strident and bespoke to compensate for cognitive decline, through greater support for the SOC generally, and comprehensibility, manageability, and meaningfulness specifically.

\section{Zeisel's Hope Versus Despair Model}

Zeisel's hope versus despair model (Zeisel, 2020a, b), as shown in Fig. 48.2, is formulated on empirical, praxis-based evidence, gathered over many years. Zeisel and his team charted the health benefits associated with maintaining hope when dealing with dementia, versus the decline that is all but assured when people meet a diagnosis by collapsing into despair. The hope model reflects salutogenic principles providing a useful window into how other SRRs fill the gap for persons living with dementia when comprehensibility is challenged and manageability confronted.

The public narrative represented in most media around dementia is one of despair, focusing primarily on what people lose as they live with dementia. Despair is a natural response to learning that you or someone you care about has dementia; the prevalent public narratives about dementia are frightening and inevitably mean a huge change in people's lives. The narrative of despair defines dementia as having no cure, leading easily to the conclusion that giving up seems like the only thing a person can do until a magic bullet can be found. The completely natural tendency to fall into despair becomes a self-fulfilling prophecy: 'if someone I love is 


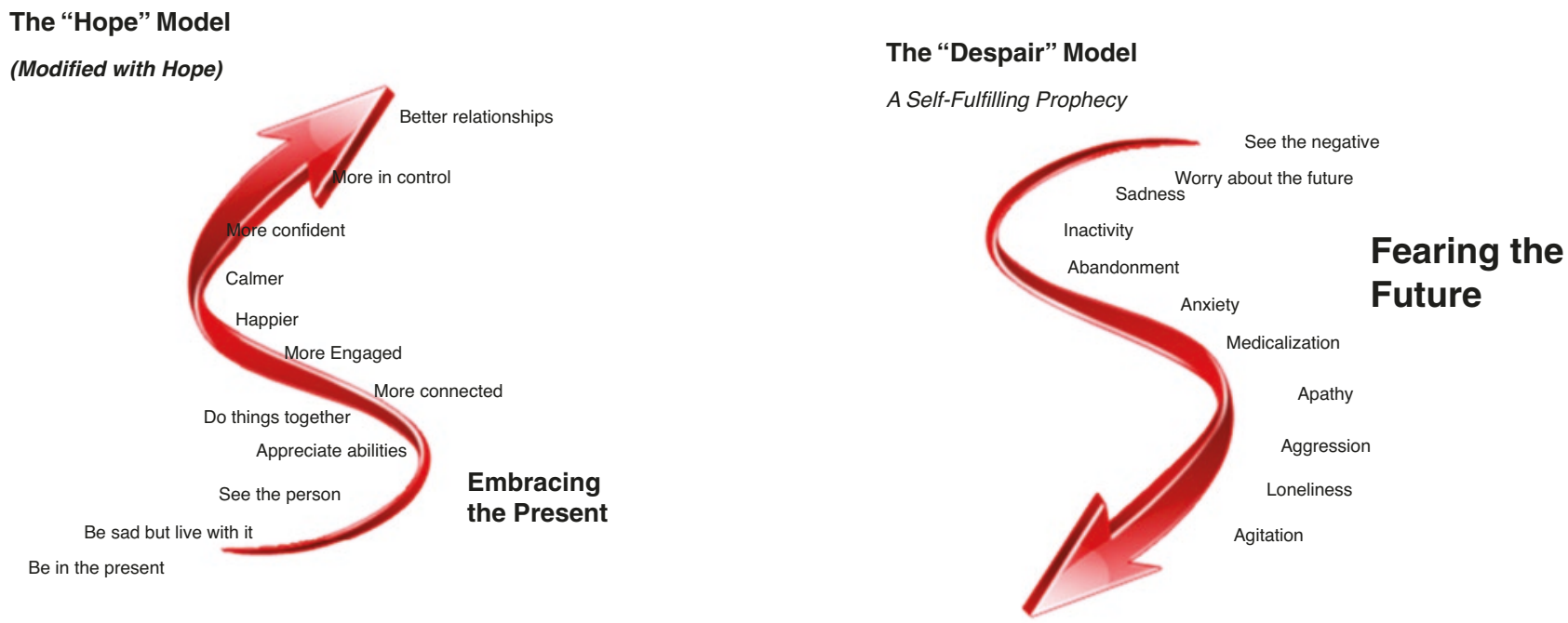

Fig. 48.2 Hope versus despair model. (Zeisel, 2020a. Published with permission of @ J. Zeisel 2020. All rights reserved)

going to lose her sense of self, how can I treat her like the person she was?' This kind of response causes people to simply give up - the opposite action we get from meaningfulness. This very normal attitude represents a lapse into meaninglessness. When meaningfulness is decimated, the illness accelerates triggering many disturbing experiences.

Hope, on the other hand, establishes a positive narrative even when all else appears to be stacked against us. In salutogenic terms, hope fills the void caused by memory-related losses and loss of comprehensibility generally. Hope enables us to maintain (and even foster) the 'dynamic feeling of confidence that one's internal and external environments are predictable and that there is a high probability that things will work out as well as can reasonably be expected' (Antonovsky, 1987: xiii). Hope reflects our impulse to live and thrive (meaningfulness) and with it the power to stay present, curious, engaged, and creative. In other words, hope provides a scaffold for meaningfulness, so it is not lost with dementia. Hope functions as a scaffold for comprehensibility, thereby supporting meaningfulness - the impulse to figure out how to make the most out of life's situations and challenges.

In the hope versus despair model (Fig. 48.2), hope is not a vague notion, wishful thinking, or ungrounded optimism. It is the positive knowledge that each of us can make a difference in our and others' lives: understanding that a dedicated community armed with appropriate design and engaging care programmes can make a positive difference. Counter to despair, hope enables greater confidence, connectedness and well-being. It is little wonder that hope leads to different outcomes than despair. How a person thinks about the future is a major determinant for how their future evolves - it is genuinely a 'self-fulfilling prophecy'.

\section{Design Approaches: How They Can Help?}

The built and natural environments can help people live life meaningfully with a true sense of agency until the end. Physical and social environments are not passive elements in life as many since Descartes believe them to be.

Descartes considered the brain an organ to transmit messages from the earthly plane to a detached and ethereal mind. In this view, architecture is an unconnected and passive thing to observe (Descartes, 1641 (tr. 1986)). This idea stuck tenaciously until the Second World War, when psychiatrist Victor Frankl observed that while some people fare reasonably well by maintaining positive social connections, ambitions and outlooks, others deteriorate very quickly in identical aversive circumstances (Frankl, 1963). Frankl's 'natural' experimental conditions were the Nazi concentration camps Theresienstadt, Auschwitz, Kaufering and Türkheim - where Frankl himself was imprisoned.

Since the 1980s, the idea that the physical environment is a significant 'factor' in health has grown, with a slow accumulation of measurable evidence correlating the physical environment with somatic health, mental health, and even spiritual beliefs (Sloan Devlin \& Arnell, 2003; Dijkstra, 2009; Ulrich et al., 2008).

Descartes' hypothesis is today an anachronism because most health professionals see the mind housed in the brain connected to the body through a shared nervous and endocrine system. The idea that a person's social network has an impact on their quality of life is now widely accepted, even though health professionals still struggle to understand how to identify useful environmental factors, and even more so with how to 'prescribe' them. That the environment plays a role in health beyond simplistic influences (like protection 
from the weather) is growing. Evidence is plentiful that views of nature positively affect a broad range of health outcomes (Bossen, 2010; Clay, 2001; Diette et al., 2003; Hartig et al., 2014; Kaplan \& Kaplan, 1989; Larsen, 1992; Ulrich, 1984; Ulrich \& Parsons, 1990; Ulrich \& Simons, 1986). Although intuitively understood, the aetiology pathways involved are not immediately evident.

One of the brain's principal tasks is to make sense of the world and situations we find ourselves in; that is, to perceive (de Wit et al., 2017). When we look around, however, there usually is not much that is natural to be perceived; what we largely are faced with is artificial - the 'designed' environment (Golembiewski, 2016). Perception, as it is moderated by language and visual culture, leads us to perceive according to implied meanings with powerful psychological implications (Moen et al.,1995). Perceptions are also ecological: the very act of perceiving an object is difficult to extricate from the actions that object inspires (Gibson, 1979). When a person perceives an opportunity to act or think (the 'affordances' the circumstances offer), perceptions trigger an impulse to take associated actions and thoughts (Bargh \& Dijksterhuis, 2001). Choice is a cognitive process that slows and inhibits the perception-triggered action/thought process, committing it to memory - if it is inhibited at all (Bargh \& Chartrand, 1999). When perceptions lead to uninhibited (or disinhibited) actions (or thoughts), as often occurs with dementia, the ecological perception/action expressway can lead both to memory loss (Golembiewski, 2014) and to reactive behaviours and behaviours that are interpreted as symptoms of dementia (American Psychiatric Association, 2014) as well as an apparently wilful defiance of the rules that are intended to keep PLWD safe.

Much of the built environment is designed and constructed for human use. Designed affordances deliberately trigger actions and thoughts. Just about every object in a building and its context makes demands of this kind on our perceptual apparatus. An exit door in a place where people live with dementia is not an opportunity to escape; it is an invitation for residents to leave. This is how the language of design works. The way affordances like this are created and managed directs the way design makes a difference to people with dementia.

Affordances - physical, aesthetic and sensory - trigger intangible, often emotional, responses: A beautiful woodland or a park with children playing might trigger feelings of joy. A locked door might trigger anger. These responses become more pronounced with the loss of cognitive capacity and advancing disinhibition; thus, PLWD are particularly reactive to the emotional quality, aesthetics, and 'tone' of their environment (Lhermitte, 1986). When an environment is perceived as aversive, PLWD's negative reactions are prone to be stronger. Equally, when an environment is distinctively positive, people with dementia are likely to reflect this powerfully.

These dynamics have extraordinary implications for physical design and MOCs, as well as for the way we communicate with people with dementia. Seemingly innocuous choices of design features, innuendo in communication, and other subtle contextual features can elicit strong behavioural reactions. When these reactions are disturbing, they create further pressure on SRRs. Not only might this leave people prone to illness and exacerbate apparent dementia symptoms; these actions can flow through to social interactions and into treatment and management regimens which only make matters worse over the long term. It is one thing to treat individuals for an illness, and another to treat them for reactions to the very environment in which the treatment is taking place!

We can, however, change the direction of treatment by 'treating' both the physical and social environments. That is, to 'treat' the way social interactions are managed by planning them carefully within the model of care (MOC). This includes briefing carers, friends and family to respect the dignity of each PLWD, to engage those receiving care with their own care as much as possible, to rely on PLWD to lead engagement activities employing their natural and life-long skills, and by taking care that the way they and we communicate does not unnecessarily tax memory and other comprehensibility SRRs.

Zeisel's (2009) eight suggested design approaches and positive MOC strategies (Zeisel, 2020b) can be interpreted both as salutogenic interventions and as affordance management. They have been shown in practice to increase wellbeing and decrease dementia 'symptoms' and can easily be understood and enacted within the salutogenic framework. For example, the decision to hide and obscure doorways to areas that are dangerous for PLWD both reduces the need to continually restrict their access to these areas, and also decreases the demands on residents' salutogenic resources required to respond to repeatedly being told to stop using a particular door and adapt to such restrictions. A sign that frustrates residents with dementia saying, 'residents are forbidden to leave through this door' taxes the comprehensibility SRR. In salutogenic theory, an insurmountable frustration (however minor) leads to deterioration. A door that invites passage, yet is nevertheless labelled impassable, is intrinsically negative. This conflict creates an ambiguity which in turn triggers amygdala activity, leading to a cascade of deleterious downstream effects including increased anxiety, psychotic reactions, and hormonal and endocrinal imbalances that even turn into chronic illness (Sapolsky, 2017), none of which helps a person living with dementia.

Perception of negative environments depletes SRRs; conversely, positive perceptions support SRRs and therefore 
help with dementia. Some researchers point to emerging evidence that dementia may even be reversible - or at least symptoms can be reversed - under positive conditions (Francis \& Murtha, 2021). Even if dementia might not currently be curable, like autoimmune disorders, most mental illnesses, and many viruses, the best treatment involves symptomatic relief and appropriate environmental modifications to make environments better fit the needs of those with the condition (Zeisel, 2009) - in other words, support for the SRRs.

'Challenging behaviours', formerly regarded as symptoms of dementia, are now, in many cases, understood to be responses to physical and MOC stressors - and are more accurately referred to as 'responsive behaviours'. Responsive behaviours in dementia increase when faced with adversity and functional decline. Environmental stressors are strongly implicated - destinations that are around corners, for instance, are quite 'normal' architectural choices. But they force PLWD to fail even with relatively simple activities of daily life. They force PLWD to try to remember what is around the corner, and therefore rely on spatial memory - a particular challenge in dementia. Similarly, long hallways with no identifying landmarks to signpost activities along the path confuse and offer no guidance for PLWD; common rooms that all look alike make it difficult to know what is expected in each room; institutional settings make it difficult for PLWD to feel at home; lack of access to an outdoor garden means it is difficult for PLWD to feel free and connected to nature; inviting doors to no-go areas and dangerous places mean that PLWD are continually being restricted and chided; when there is no personal space to make their own, PLWD feel a sense of loss; auditory and visual pollution and confusion make it difficult for PLWD to make sense of where they are; and the absence of aids such as toilets that are high enough to use easily (with weak knees) prevent PLWD from being as independent as they can be.

Removing social stressors, which might be taken for granted in traditional MOCs, leads to more salutogenic alternatives. For example, personalised schedules that respect and adapt to each person's history and habits, in lieu of standardised schedules for getting up in the morning and going to bed at night, reinforces each person's sense of self. A person's comprehensibility SRR is supported when friends, family and carers ask bifurcated questions (e.g. 'Would you like to wear your comfortable shoes or your smart ones today?' as opposed to 'which shoes do you want to wear today?'). It helps to provide PLWD answers to questions before asking the question (e.g. 'That's Uncle Evan in the picture, do you know who that is?'). Embarrassment and other emotional problems can be avoided by refraining from the common habit of testing PLWD with questions like, 'Do you remember me?' or 'What is the name of that bird over there?'
From a salutogenic perspective, it is easy to see how poor design choices and communication practices like these break down critical SRRs, creating symptomatology and disability. When the following design approaches are respected, symptoms are passively reduced, SRRs are supported (particularly those related to comprehensibility), resulting in disabilities becoming less apparent and restrictive, with PLWD happier and more positive (Zeisel, 2013).

- Unobtrusive control of exits to dangerous places

- Walking paths with clear destinations

- Common space differentiation

- Private spaces and personalisation

- Access to accommodating secure gardens

- Residential quality

- Comprehensible sensory environment

- Support for Independence

- Support verbal communication with non-verbal communication

- Choices, 24 hours a day

In the following, photographs are used to bring life to the text because, as they say, a picture is worth a thousand words.

\section{Unobtrusive Control of Exits to Dangerous Places}

To avoid frustration and related behavioural side-effects associated with reduced comprehensibility, it is important to carefully plan affordances and the actions they are likely to trigger for PLWD. Some affordance/action relationships are desirable - such as a door that leads to a person's personal space, or a safe garden. When PLWD exercise such 'choices', their independence as well as their comprehensibility is maintained. Other affordances, however, are undesirable such as when a door leads somewhere risky - to a busy street, into mechanical or electrical rooms or to an unfenced garden. Undesirable affordances such as these need to be made less inviting and, wherever possible, well camouflaged (Fig. 48.3). Memory-taxing, complex locking systems can be added for additional security, typically a numerical keypad somewhere other than by the door - ideally, in a place that directs PLWD away from the exit and towards a destination that offers an attractive and desirable alternative affordance. For complete safety (which is required to provide residents with independence and freedom of movement within a residence), unobtrusive access control of some sort is also needed for external windows and fences (Fig. 48.4). When doors to safe and desirable places look and feel to residents like a front door, are as inviting and are even designed to provide attractive views to what is beyond (a door between a residence and a garden for instance), residents will naturally use that door rather than ones that are less evident and less inviting. 
Fig. 48.3 A door blended into the wall colour, with a keypad around a corner and behind furniture does not communicate 'please enter'. And if PLWD do recognise it as a door, finding and using the keypad requires memory and sequence - the kind of cognitive processes that

(Photograph (C) J. Zeisel 2005. Published with permission. challenge PLWD. All rights reserved)

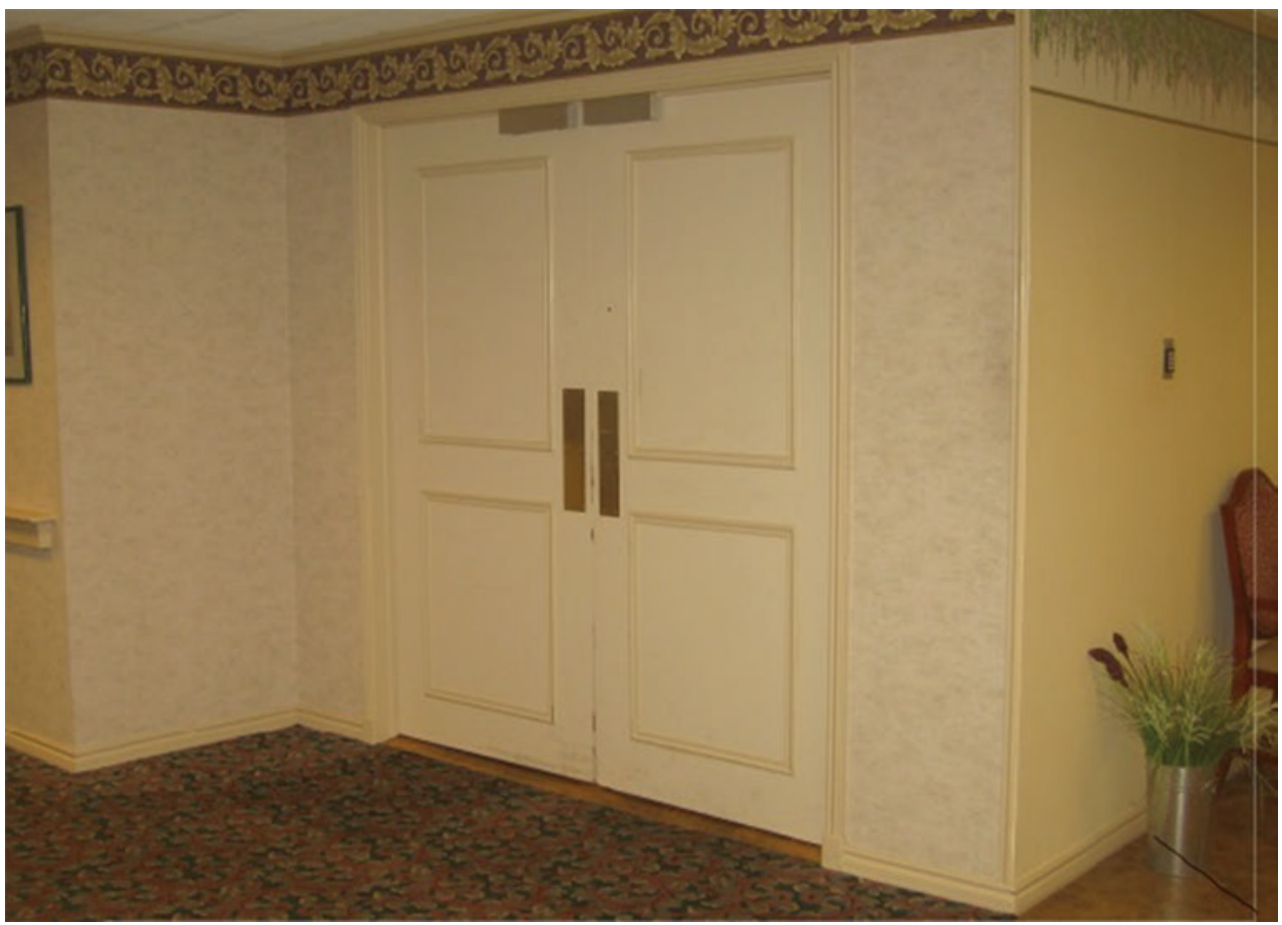

Fig. 48.4 An opaque garden fence, obscured by vines, provides security because of its height and the vines which do not speak of an invitation to explore the world beyond. (Photograph () J. Zeisel 2005. Published with permission. All rights reserved)

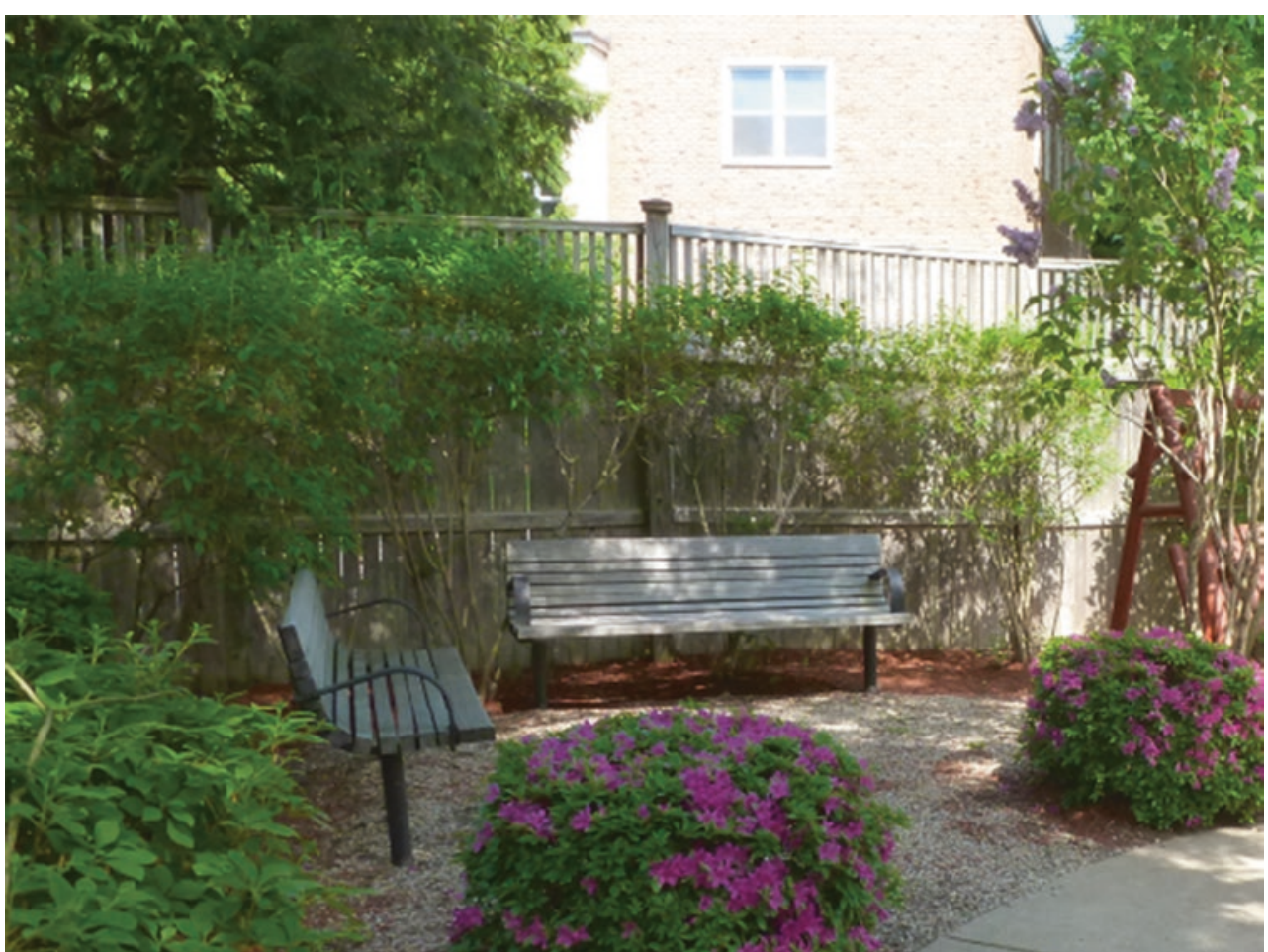

Doors with transparent panes invite PLWD to look out and seek whatever is beyond. When a transparent door is an exit or otherwise leads to somewhere dangerous, the PLWD who try to use it are not attempting to escape - the problem is one of design. The door communicates 'please come through', while the rule says 'NO EXIT'. This is equally the case for doors that have signs on them - any sign at all (whether the sign says 'NO ENTRY' or 'THIS WAY OUT') - indicating that there is a door, which means there is somewhere to go, regardless of what the sign reads.

MOCs that promote continuous personalised engagement and activities for PLWD are complementary to good exit control design. PLWD engaged in interesting and meaningful activities have less desire to leave. Engagement replaces anxiety and the desire to get away (Zeisel, 2020b). 


\section{Walking Paths with Clear Destinations}

In his seminal work, Image of the City, Lynch (1960) identifies five critical elements for wayfinding: paths, edges, districts, nodes and landmarks. Each of us uses these environmental elements as tools to understand our milieus and for wayfinding and orientation - all-important for comprehensibility. For PLWD, these elements are even more important.

When PLWD know where they are and where they are going, they walk with purpose. Meaningful cues give a sense of being somewhere specific. Visible destinations - particularly those they enjoy and are interested in - at the end of corridors and paths provide PLWD with purpose and knowledge.

Corners and curves in 'wandering loops' obscure destinations and are confusing. PLWD are encouraged to know where they are going and why, by being provided with 'nodes', (that is, when recognisable and meaningful objects including photographs and furniture from people's own lives and spaces overlap with meaningful activities at destinations). This supports the comprehensibility SRR and, as demonstrated in Figs. 48.5 and 48.6, the other SRRs as well.

Lynch (1960) identified landmarks as particularly important for orientation. If you are asked to find your way from where you are now to your car or back to your home, you will find yourself thinking in terms of landmarks - 'turn left at the [landmark] corner store'. Cues along a path and visible destinations serve such a landmark function for PLWD, for whom landmarks need to be more recognisable, regular and meaningful. The result is that in such environments PLWD 'walk' purposefully rather than 'wander' aimlessly. Our curious brains naturally search for purpose and direction. When we are confused about where and why we are someplace, landmarks and destinations provide meaning to this search for purpose.

MOCs that provide attractive engagement opportunities for individual or group activities at visible destinations further support orientation and wayfinding. This MOC intervention also supports the common space differentiation design criterion.

\section{Common Space Differentiation}

Residents, even those living with dementia, are expected to behave socially and appropriately. To achieve this, designers can organise spaces around another of Lynch's basic wayfinding elements - differentiated areas - the residential equivalent of 'districts'. Common space design emphasises 'local' [district] qualities and opportunities for engagement. Interior 'districts' with thematically associated nodes and landmarks combine to create 'behaviour settings'. To an extraordinary extent, the language of behaviour settings determines the acceptable limits of behaviour in an area, especially when people are uninhibited (children) (Barker \& Wright, 1954) or disinhibited (a common feature of dementia) (Golembiewski, 2013b). Some common space interior 'districts' might be more sociable, others quieter and more contemplative, others will communicate specific activities. Kitchens, dining rooms, music rooms and other shared com-
Fig. 48.5 Memory boxes on walls and a decorated Christmas tree at end of a corridor makes a corridor a meaningful and social space. (Photograph @ J. Zeisel 2005. Published with permission. All rights reserved)

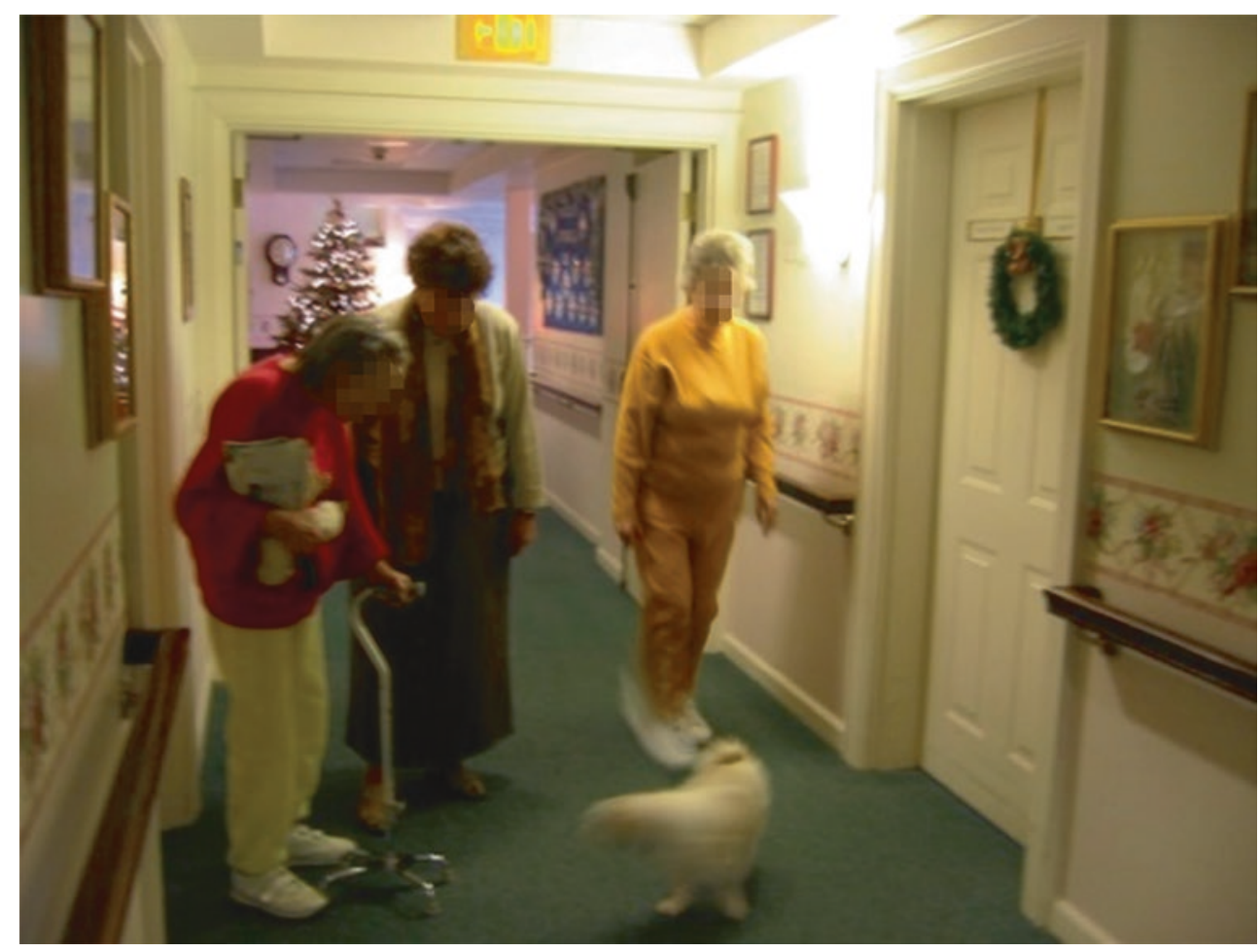


Fig. 48.6 Familiar museum portraits, furniture and open doors leading to engagement spaces support the comprehensibility SRR. (Portrait (left): Migrant Mother, Library of Congress, Prints \& Photographs Division, FSA/OWI Collection, LC-USF349058-C. Photograph (C) J. Zeisel 2005. Published with permission. All rights reserved)

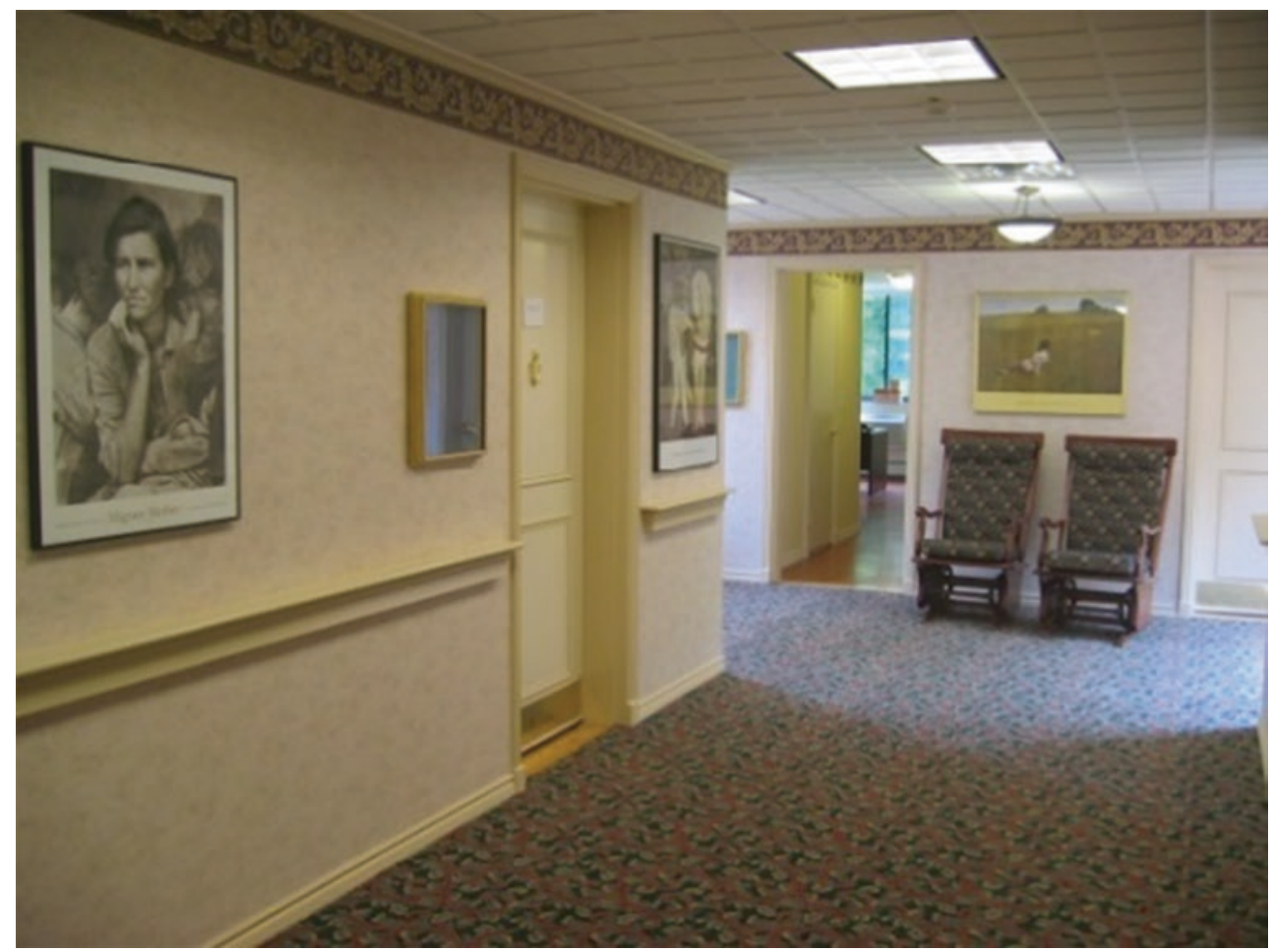

mon spaces, designed with the appropriate character, messages and landmarks, communicate and reinforce their intended uses (Figs. 48.7, 48.8, 48.9 and 48.10). Scale, furniture and built-in features and fixtures communicate to residents what is appropriate in these spaces - preparing meals in the kitchenette, serving and eating meals in the dining area, films on a video screen in the living room, planting seedlings in the greenhouse. When there are two or three such places in a shared residence, each with a different character, residents can choose between clearly different common areas rather than unnaturally spending all day in only one or in more than one of several places that all feel the same.

\section{Private Spaces and Personalisation}

If a person's bedroom - their personal territory - is to support a salutogenic sense of coherence (SOC), it must provide visual and audio privacy. Bedrooms provide an opportunity for refuge and respite. While the need for privacy is the same for all humans, the need is redoubled when people require more time to process sensory and emotional information.

No one's memory is perfect. All of us use cues in our environment to remind us of the memories we want to recall.
Papers on the desk remind us to work on something. Leaving our umbrella near the front door reminds us to take it when it rains. We use personal mementoes to remind and reinforce our 'sense of self'; who we are, where we live and work, and what we care about. Items we choose to surround ourselves within our living and work environments sharpen our memories about events and times we consider important. They also communicate to others a sense of who we are. The same is true for people with dementia - only more so, yet unfortunately, institutional residences sometimes remove possibilities for personalisation. The more PLWD are surrounded by photos of family, mementoes from trips, or artwork they have created or collected, the more they remember the people and events involved and the more they are aware of their creativity (Figs. 48.11 and 48.12).

MOCs that respect the identity and abilities of each person support personhood just as personalised private spaces do, for example, when residents are addressed as they wish to be addressed - 'Dr. Watson', 'Bill', 'Mrs. Jones', 'Reverend Judith' and so on. It stands to reason that these communication approaches reinforce each individual's sense of self. Care staff who make it a point to be familiar with and purposefully use in conversation a person's personal, family, and professional history, further support personhood and related SRRs. 
Fig. 48.7 Kitchen-like décor as shown here indicates what functions a room serves.

(Photograph @ J. Zeisel 2005. Published with permission. All rights reserved)

Fig. 48.8 Kitchen-like décor indicates that it is appropriate to wash dishes and set the table there. (Photograph (C) J. Zeisel 2005. Published with permission. All rights reserved)
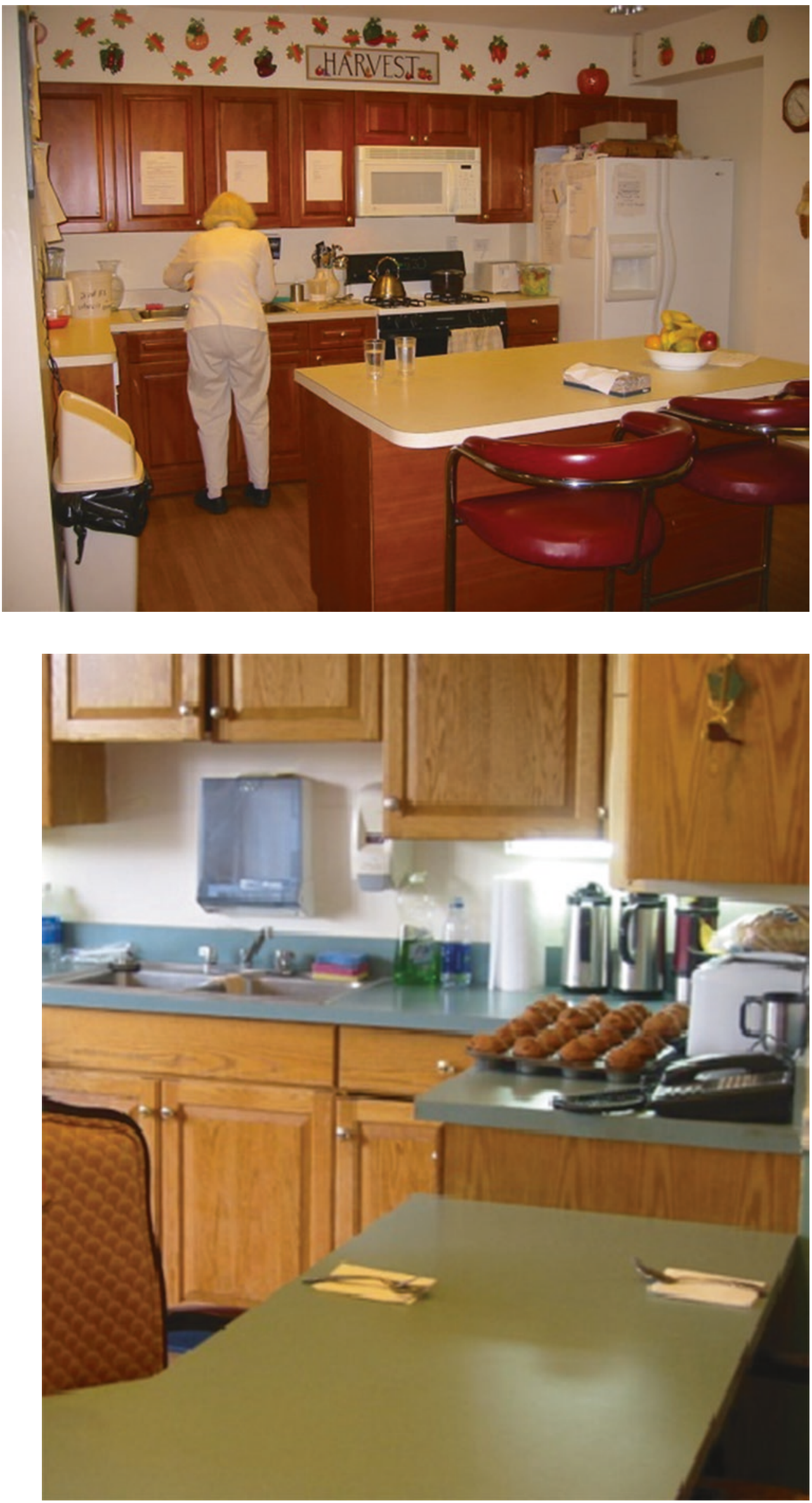
Fig. 48.9 Music room.

(Photograph @ J. Zeisel 2005. Published with permission. All rights reserved)

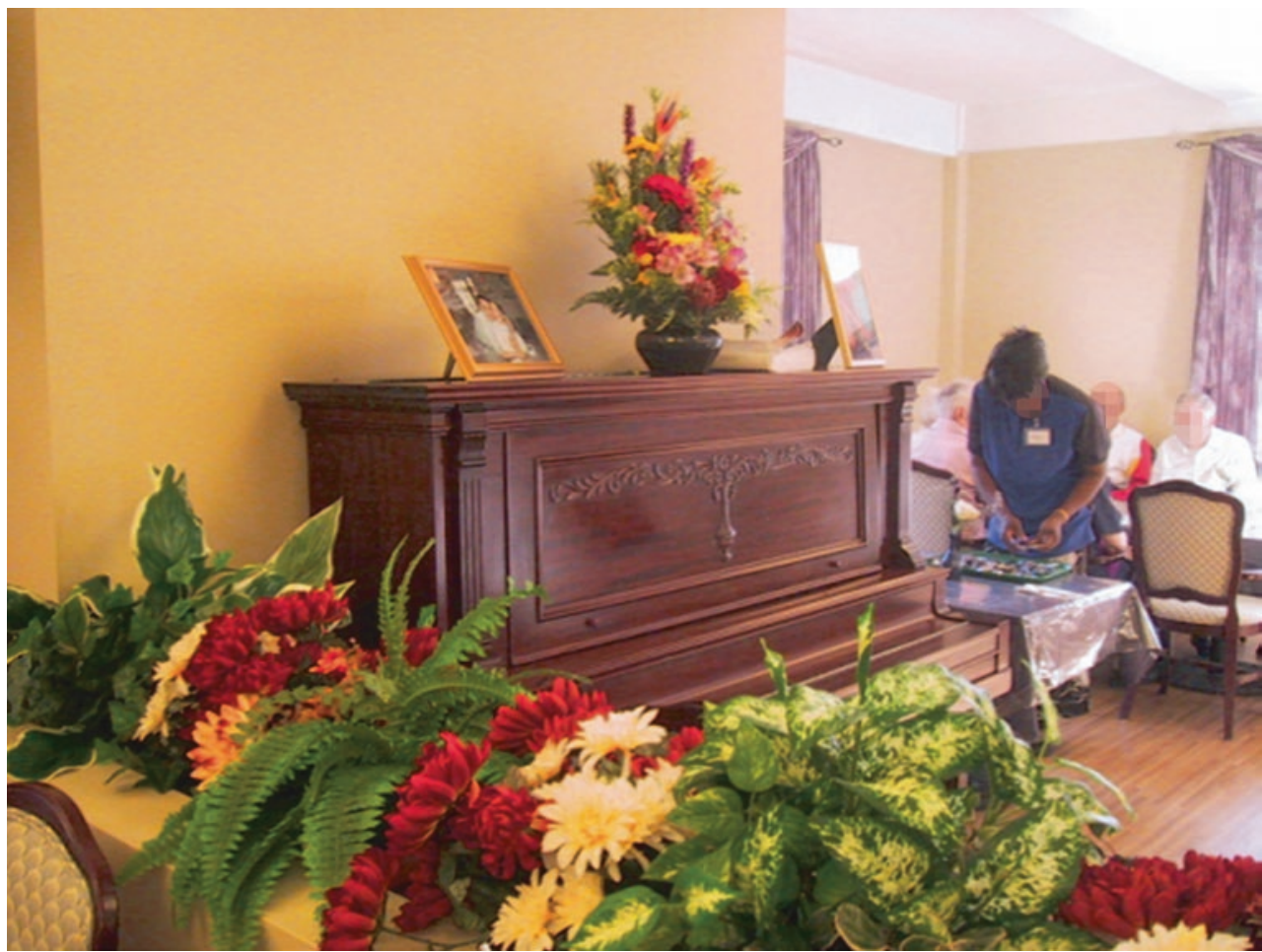

Fig. 48.10 Hairdresser salon. (Photograph @ J J. Zeisel 2005. Published with permission. All rights reserved)

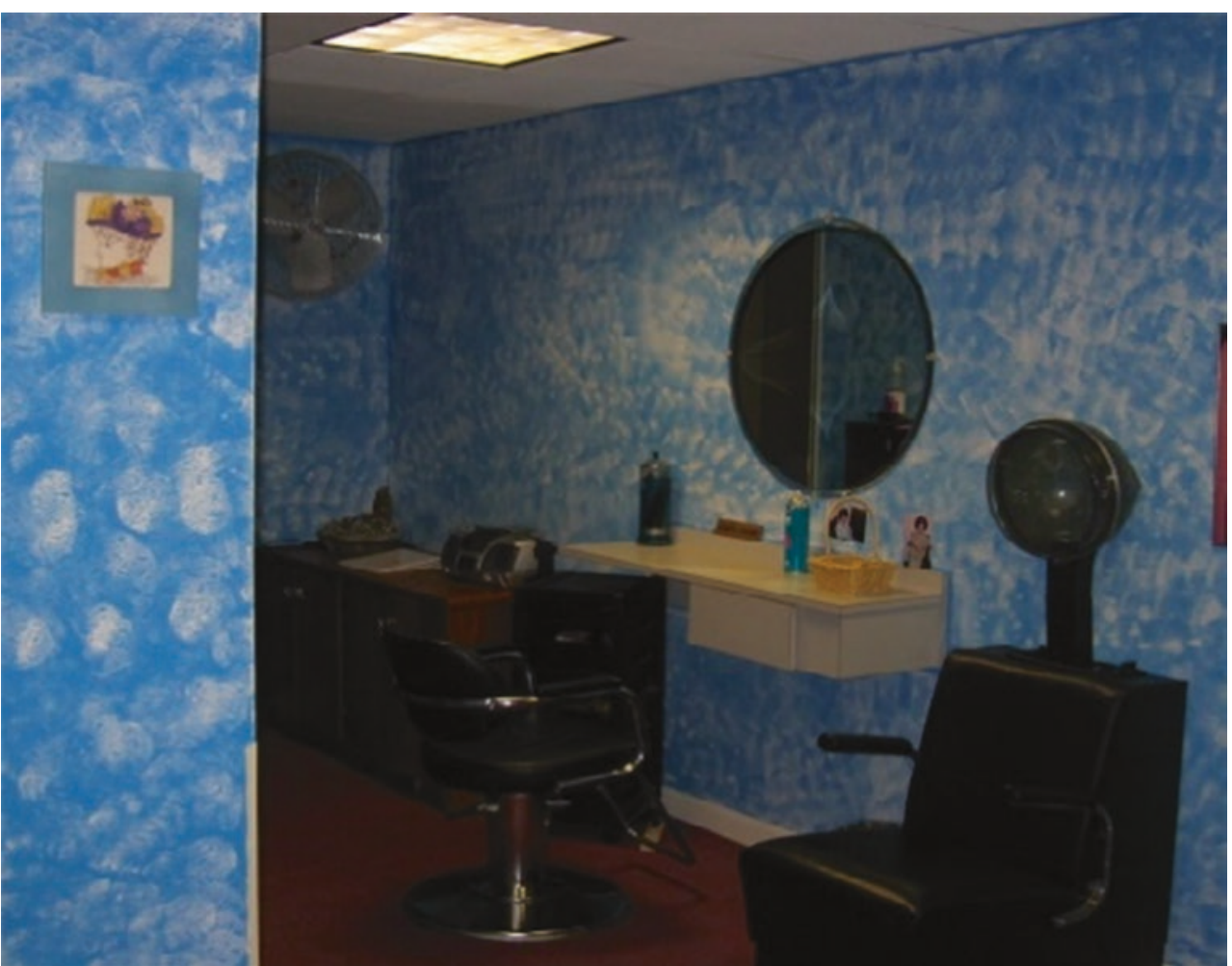

\section{Access to Accommodating Secure Gardens}

In residences for PLWD, gardens are a necessary fourth common area - albeit without a roof. Being outdoors in sunshine sets our diurnal clocks, thereby reducing time disturbances and 'sundowning', a phenomenon where reactive behaviours intensify as the sun sets in the evenings (Gnanasekaran, 2016), when they are reminded 'it is time to go home from work' or 'it is time to plan for evening activities'. To achieve these ends, outdoor areas for 


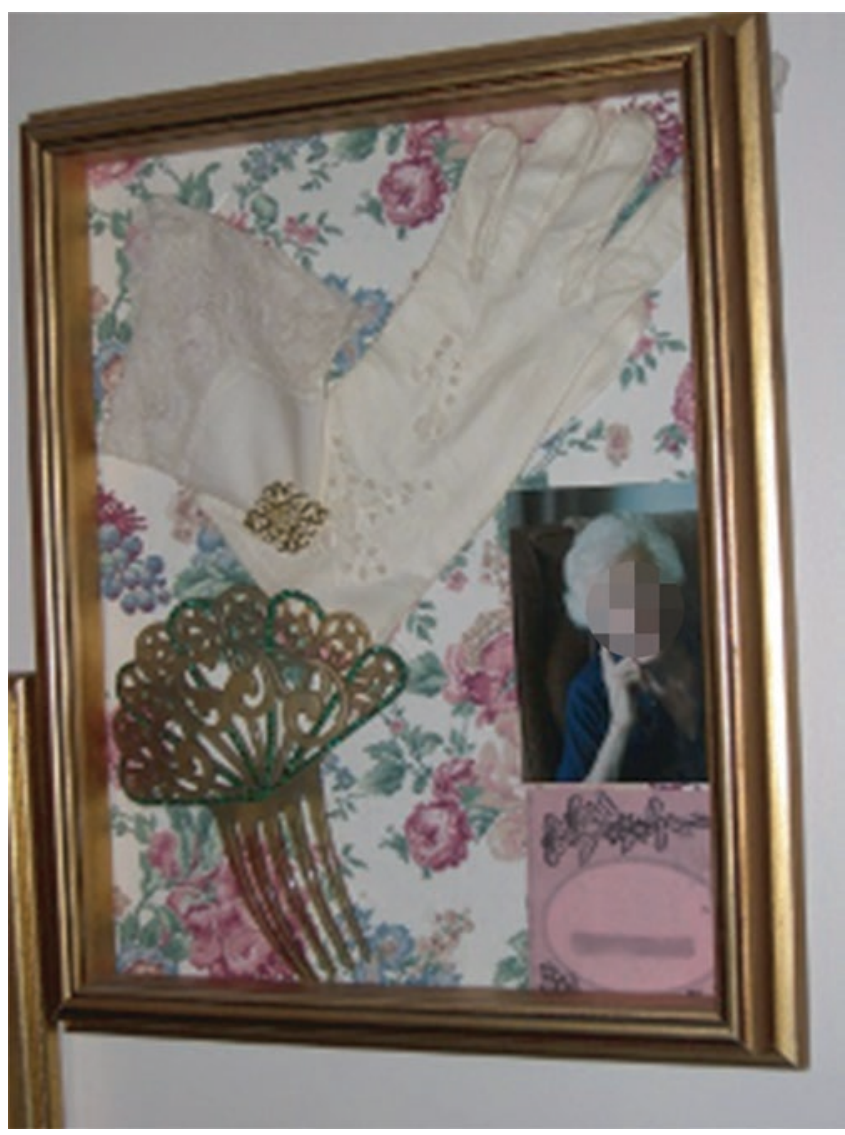

Fig. 48.11 Memory shadow boxes outside residents' rooms (Photograph @ J. Zeisel 2005. Published with permission. All rights reserved) people with dementia must be safe to use, include imaginative and engaging elements, provide clear direct walking paths with no ambiguous choices, and be secure from potential public dangers beyond the garden such as car traffic (Fig. 48.13).

The more gardens are accessible and inviting, and the more staff understand just how important gardens are, the more people with dementia will get outside and maintain their sense of time and the seasons. In residences for PLWD, garden design and enclosure decisions are intimately linked to the garden's governance which also has to be carefully planned, including decisions such as when the door to the garden is unlocked; who controls the key; and whether residents or staff do the gardening. Decisions like these are ultimately as important for accessibility for PLWD as providing ramps for wheelchairs.

Gardens often serve as the main outside place to which PLWD have ready access (Fig. 48.14). When a garden is truly secure and safe, it can be used independently without a care partner present. Security is essential for staff to feel comfortable leaving the door open and providing access. If security is not $100 \%$, when fences are too low, or if there are attracting views out to parking areas, busy streets, or nearby affordances, staff members who naturally want to protect those in their charge understandably restrict residents' access to a garden except under tight supervision. The more a garden is designed safely and therapeutically, the more the person with dementia feels comfortable and in control of herself there.
Fig. 48.12 Personal furniture, photos and mementoes all give the person as well as others who visit a sense of the person as a whole person. (Photograph (C)

J. Zeisel 2005. Published with permission. All rights reserved)

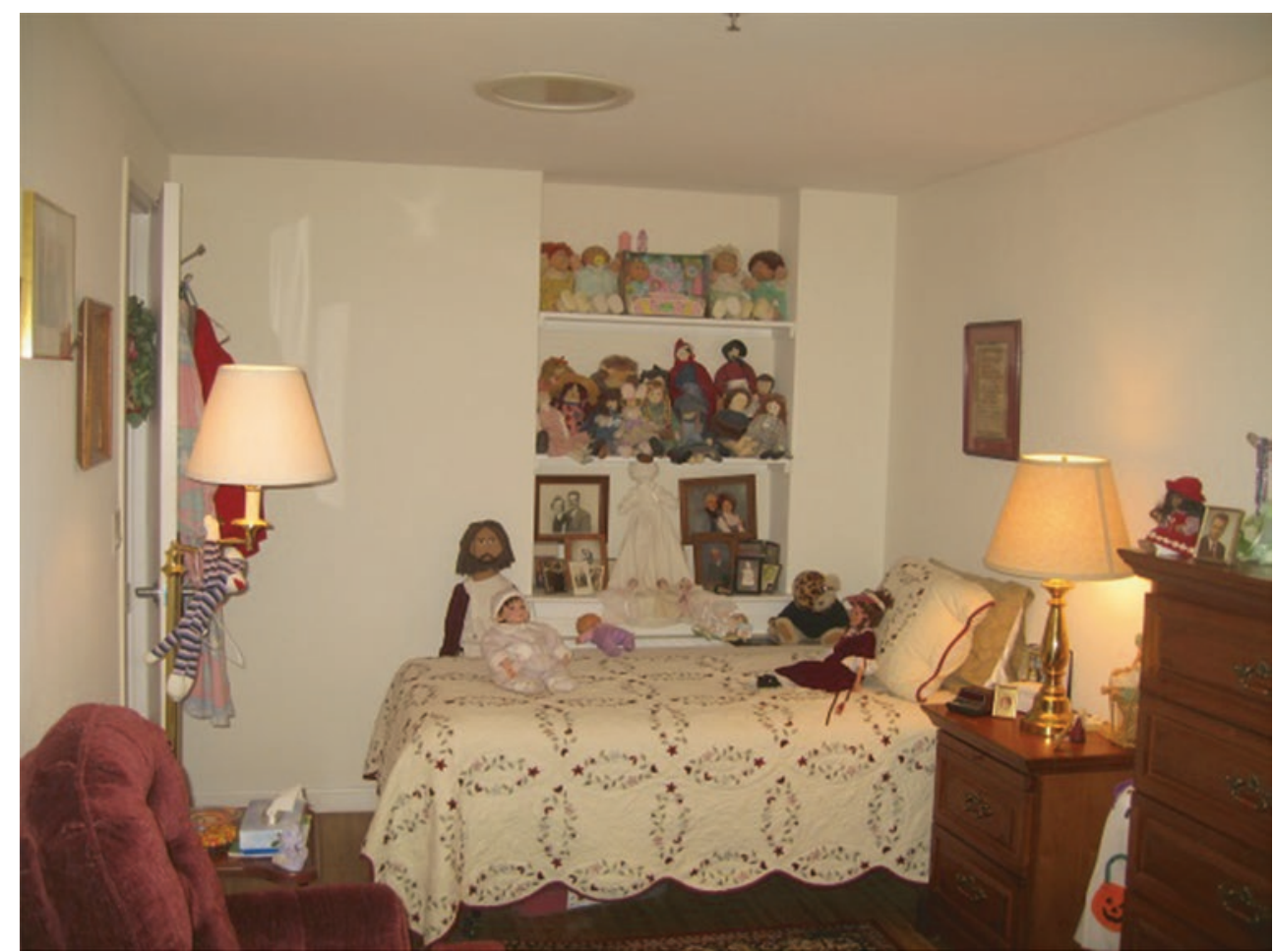


Fig. 48.13 Landmarks, self-evident walking path, and patio furniture all help define therapeutic gardens. (Photographs (C) J. Zeisel 2005. Published with permission. All rights reserved)
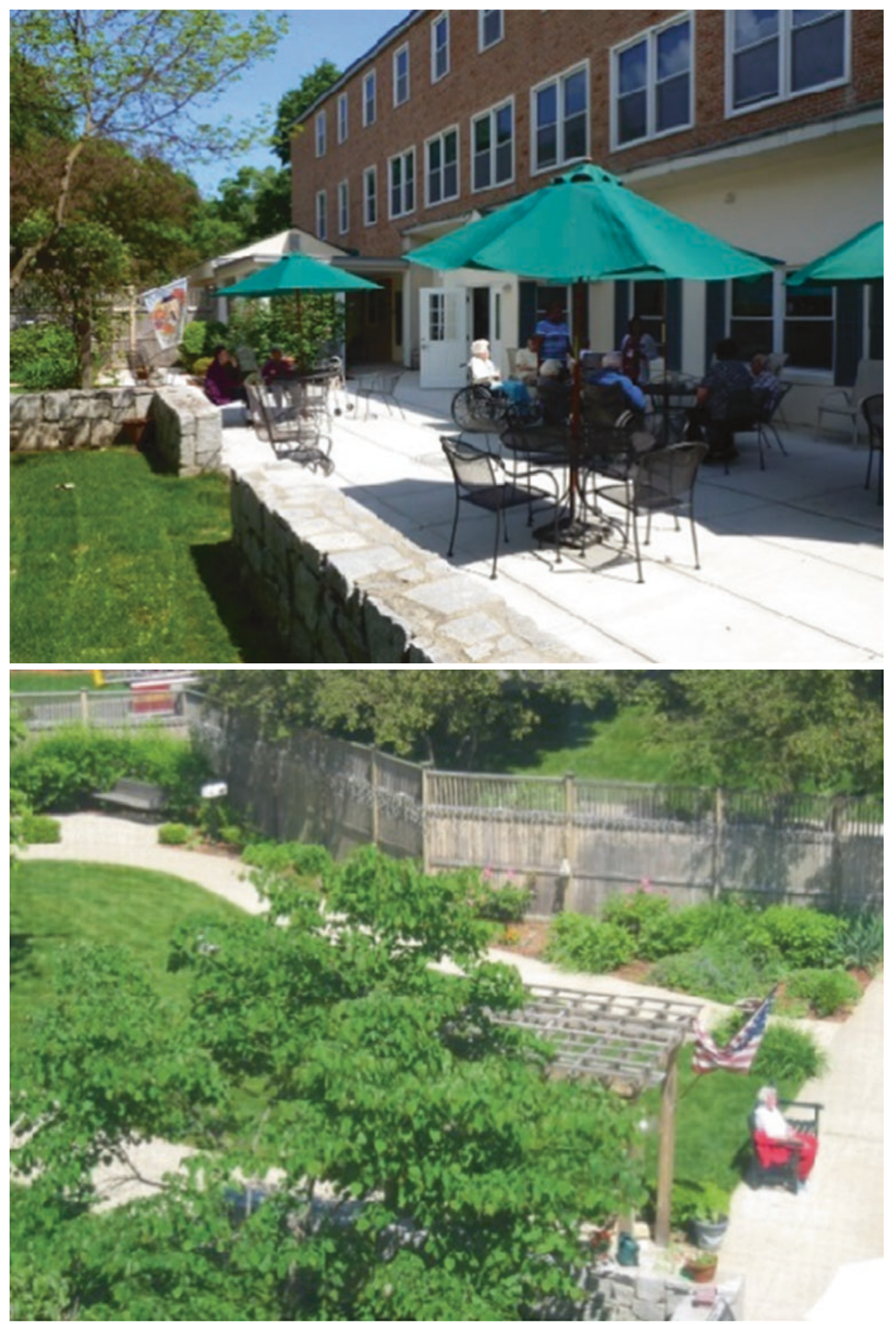
Fig. 48.13 (continued)

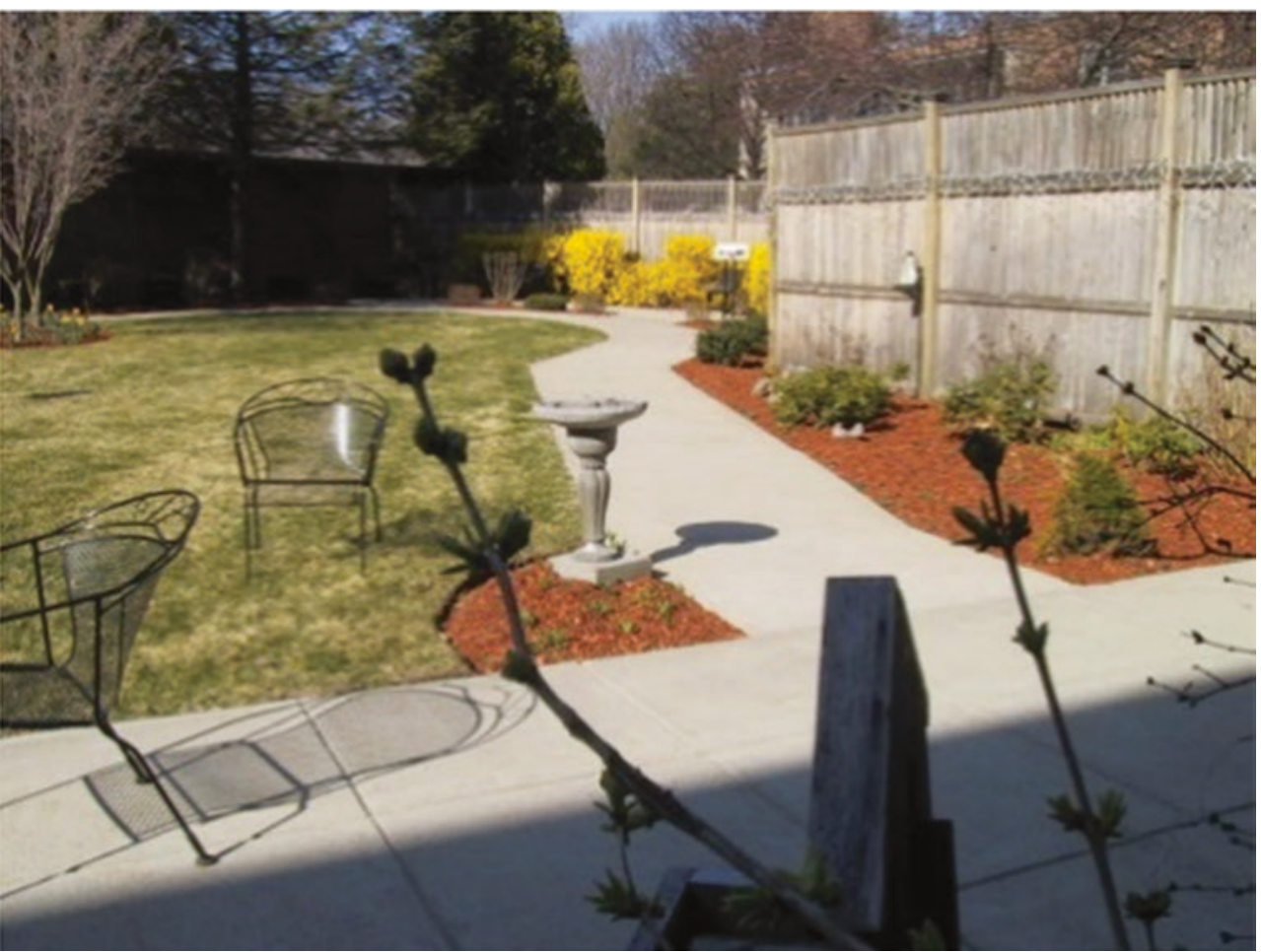

Fig. 48.14 Public parks such as Riverside Park in New York City can provide enough interest to make it a therapeutic garden venue. (Photograph @ J. Zeisel 2005. Published with permission. All rights reserved)

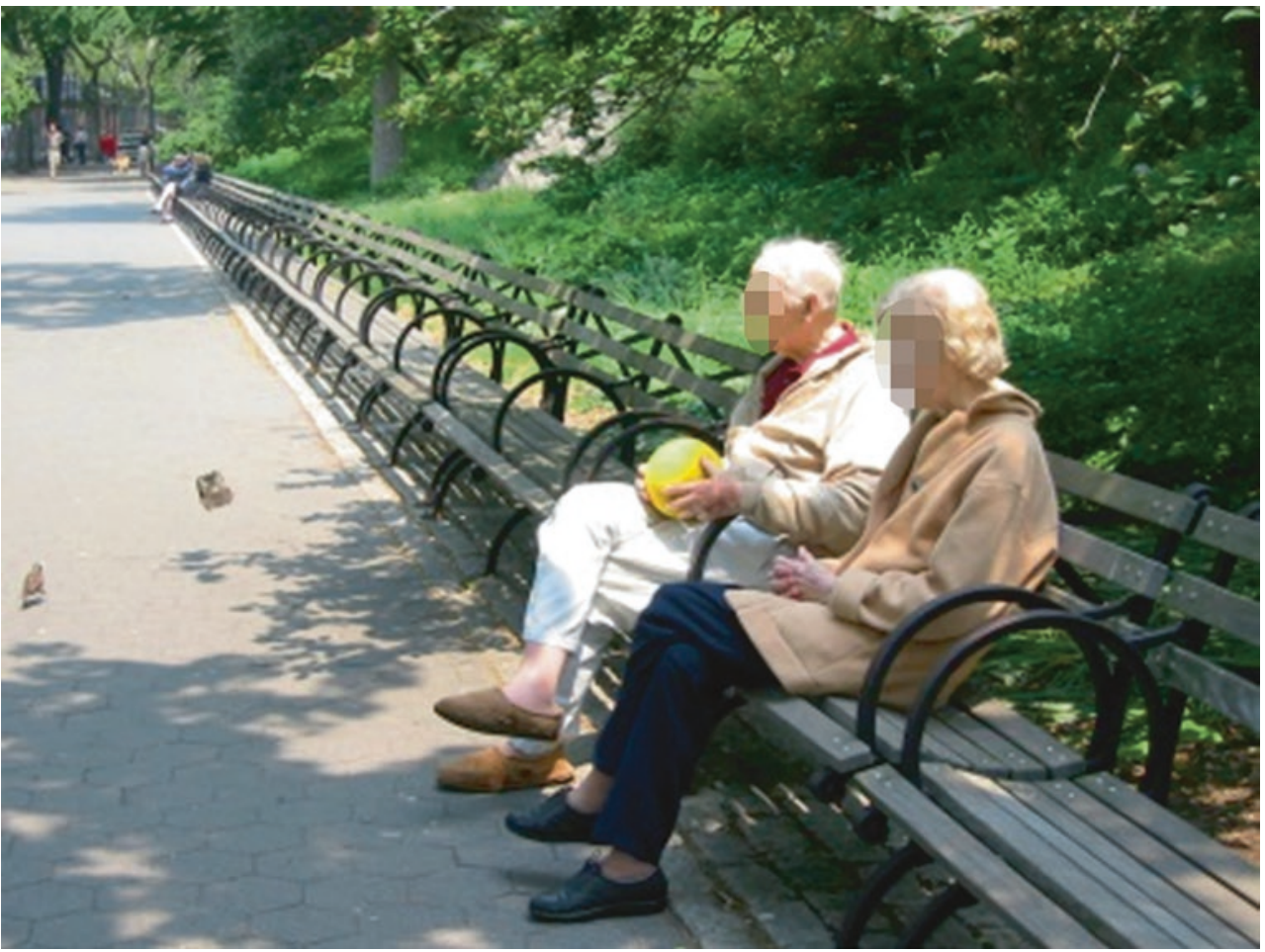

An MOC that encourages freedom of access to the outdoors and nature is also more likely when passive surveillance of the entire garden is possible from inside. To achieve this, carers must be trained to be vigilant to what is happening in the garden - on the lookout for both positive interactions and possible falls or upsets. Even when there is good outdoor access, benefits of gardens can be further enhanced with affordances organised outdoors such as barbeques, family gatherings, playgrounds for children, and harvests that continually remind PLWD about their outdoor spaces. 


\section{Nature and Internal Clocks}

The Biophilia Hypothesis (Wilson, 1984) holds that our brains are hard-wired to respond to nature. A baby does not have to be taught to enjoy the warmth of the sun on her skin in the summer or the pleasure of looking at and even caressing a tulip in the spring. Similarly, no one needs to teach us to be afraid and protect ourselves during a ferocious thunderstorm. Being outdoors gives people with dementia the opportunity to use their hard-wired understanding of nature.

A basic and well-accepted principle of design for care environments is to invite sunlight and 'views of nature' into a residence; the effect of nature on health outcomes being amongst the most well-known and evidence-based effects (Hartig et al., 2014). Due to safety concerns, low staff levels, or lack of interest, gardens are too often kept in sight but out of bounds (Golembiewski, 2013a). An inability to access nature while a person is often ambulatory causes frustration, eroding the meaningfulness SRR; such an affordance denial ultimately conflicts with our very will to live. Access to these spaces, on the other hand, feeds the same SRR with a sense of joy. When a garden is kept locked, the message of hope that the garden conveys is dashed, leaving a clear message that the person is being restrained and that staff are there to obstruct movement rather than provide help. While views of nature are essential, if a garden is glazed in, yet inaccessible, it may be better if there were no garden at all (Golembiewski, 2010).

\section{Residential Quality}

When the environment is familiar and PLWD personalise their personal space with their objects and mementoes, it helps them feel at home and in control. Rooms of a residential scale, not institutional in scale, homelike furniture and fixtures, and residential rather than institutional decorations and colours all help achieve this end. Families of residents, as well as those care partners working at the residence, must reinforce this message: the residence where PLWD live is residents' 'home' which staff and visitors must respect. Family and staff understand this best when the environment is designed to look like a home from the outside (the typology might be that of a large family house); and when family members are welcomed and accommodated. Feeling guilty about 'putting parents into a place that looks an institution' may even keep them from visiting or behaving appropriately. The many shifts in life associated with a condition like dementia are disconcerting enough without the physical environment and MOC reminding us of these changes. One of the ways the environment can soothe transitions and "normalise' new living arrangements is to look like and feel like 'home' whenever possible (Fig. 48.15).
MOCs that emphasise homelike affordances such as pets, accessible kitchens, and a hearth reinforce residential quality. Most important, however, is the way care partners themselves feel and act - for example, making a habit of knocking on the door of a person's personal space and asking if they might enter, and respecting that the entire residence is 'home' to PLWD and as carers behave as guests rather than entitled users in their workplace.

\section{Comprehensible Sensory Environment}

Residents feel most comfortable in settings where they comprehend what they see, hear, smell, and touch. This does not mean designing environments that match long-term memories, but rather that the messages sent by the colours, sounds, smells, and textures are coherent and multifactorial (Fig. 48.16). Like anyone else, PLWD comprehend their environments through all their senses - sight, feeling, the sense of smell, hearing, and even taste - not just one sense. People in old age (and especially with dementia) are even more reliant on multimodal perception because age and illness weaken sensory perception and cognition unevenly, and alternative modes of perception are used to compensate for these losses. Design can be used to intensify the senses that speak of wholesome normalcy. The greater the coherence amongst sensory inputs, the greater the understanding a person has of their environment.

MOCs that offer a full calendar of special affordances such as celebrations, special foods, and holidays further foster comprehensible engagement. To be most effective, these must be carefully individualised according to the cultures and life narratives of residents. Religious holidays do not have to be the only drivers of such events. Positive emotions can also be summoned with rituals like ceremonially raising a flag in the morning, and bringing it down in the evening (Perkins, 2013).

\section{Support for Independence}

Most of the aforementioned details relate to the comprehensibility and meaningfulness SRRs, but manageability is also significant in contributing to a strong SOC. Manageability, closely linked to the degree of a person's independence, is improved by such elements as lean rails along corridor walls, toilets high enough to rise from without help, and chairs with arms to lift oneself by (Fig. 48.17). The failure to provide such simple affordances is akin to restraint. If people with arthritis are put into deep recliner chairs, they require help to get out, and without such help, they may as well be chained in place (The Royal Commission into Aged Care Quality and Safety, 2019). When environmental conditions and MOCs 
Fig. 48.15 Family

photographs (top), personal furniture and pets (bottom) provide a strong and recognisable sense of 'home'. (Photographs (C) J. Zeisel 2005. Published with permission. All rights reserved)
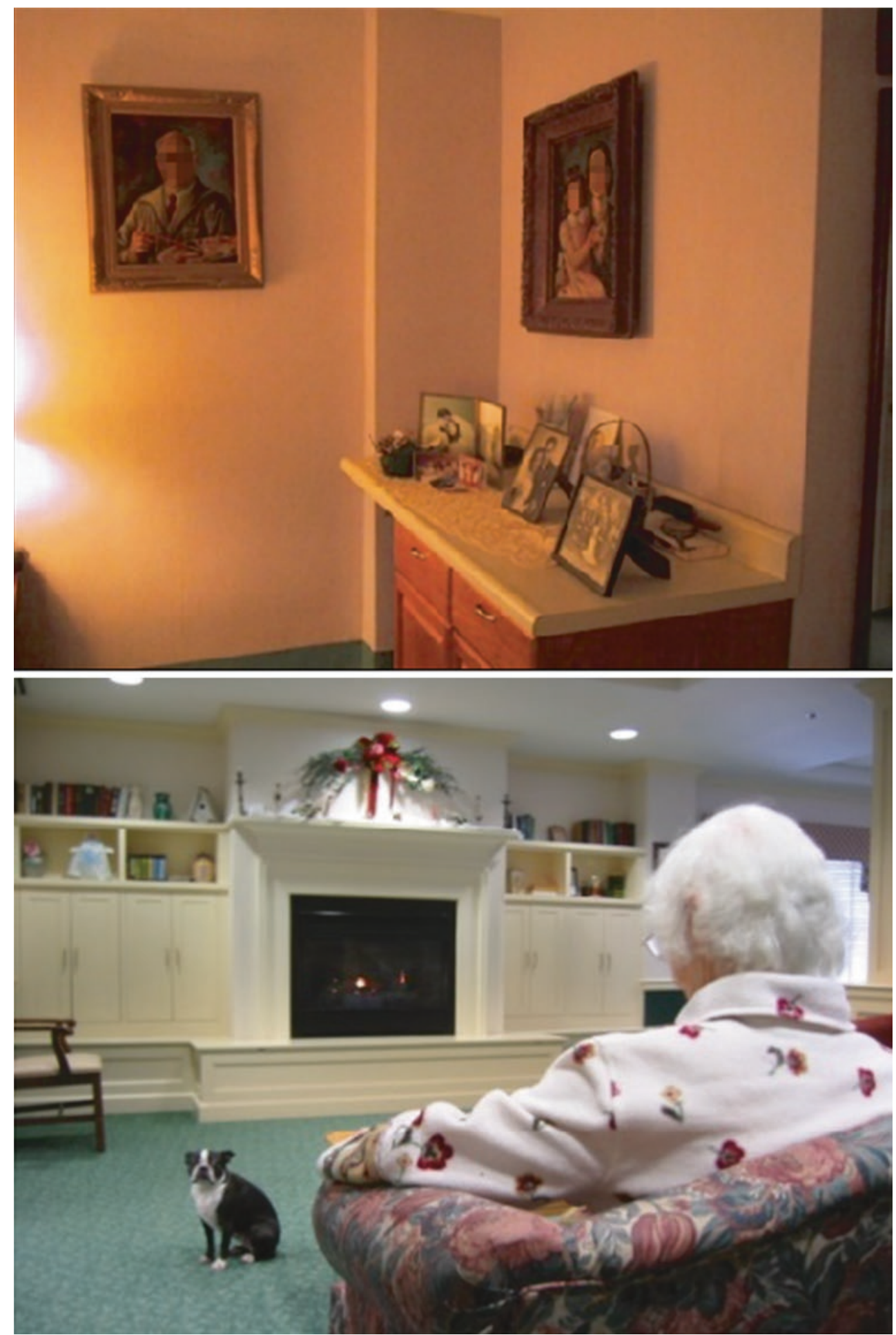

support people's use of the capacities they still have, they remain as independent as possible for as long as possible, whether or not they are living with dementia.

To deliver independence-supportive care is not easy because carers tend naturally to balance risks that accompany such independence - the risk of a person catching a cold in the garden when the weather is poor, falling when walking independently, getting upset when they try to do something and then discover they cannot. Rather than restrict activity that might cause such consequences or blankly accept these consequences, care partners must be ready to respond when such setbacks happen - rather than predicting the problem and pre-emptively protecting the PLWD by reducing their independence. This strategy built into the 
Fig. 48.16 The smell of recently baked muffins remain a coherent sensory experience for PLWD. (Photograph (C) J. Zeisel 2005. Published with permission. All rights reserved)

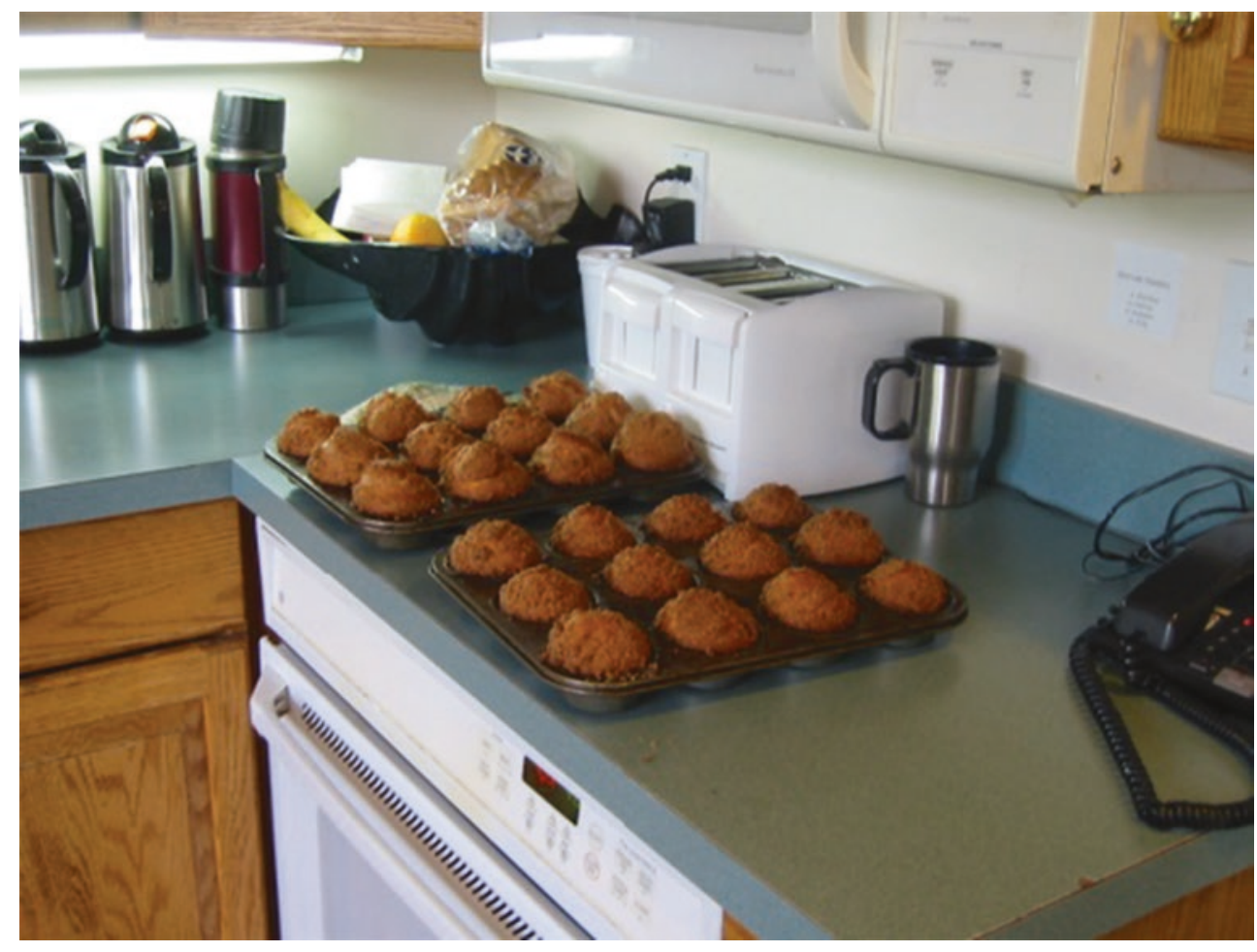

MOC, can even be documented in a shared risk agreement with the PLWD and their families.

\section{Support Verbal Communication with Non- verbal Communication}

When happy and settled, PLWD appear to others quite normal; in many ways, they genuinely are. Unfortunately, this often leads visitors and carers to test the PLWD to check 'how bad' or 'how improved' their condition is. Verbal communication generally can be treacherous for PLWD and is so much worse when someone attempts to plumb the depths of a person's memory loss. PLWD may drift when speaking and attempt to recall specific memories that are not readily accessible. This can be stressful. Visitors and carers can make communication less stressful by filling unavailable memory gaps with relevant information before asking a question, having a laugh with the person, or ignoring or making light of simple mistakes. Visitors and family who dig in and challenge the PLWD by asking them to remember something specific on cue set the PLWD up to fail. Typical examples include, 'Do you know who I am?' or 'Where do you live?' Such challenges are extremely stressful in salutogenic terms - like pulling the comprehensibility rug from under a person's feet.

Communication is often most effective when multifactorial and supported by contextual aids. For example, visual cues and delicious smells together are better at suggesting it is dinner time than just telling someone to come to dinner. Emotionally salient contextual cues are especially important. The daughter of a PLWD who does not want to create anxiety must not ask, 'Do you remember who I am?' Demonstrating who you are by introducing yourself by name to your mother (although it may seem silly to you, it is no less odd than asking a parent if they remember who you are). Being kind and affectionate also reduces anxiety, which makes remembering easier. Carers, therefore, should be caring (Zeisel, 2009). Similarly, if you know what a PLWD has done in their earlier lives, this can be celebrated with them. When visiting an art gallery with a retired ambassador, for instance, the question, 'What artworks would you select for a new embassy building?'

\section{Choices, 24 Hours a Day}

Choices of good things to do is a key meaningfulness SRR it is more than just nice to be offered a choice of good things to do. Throughout our evolutionary history, we have been kept busy much of the time doing what our immediate needs require. But once the grain has been harvested and all other tasks have been completed, we are presented with a rare moment of choice: What would we like to do now? These moments allow us to stop, consider, and dream, engaging the anterior regions of the frontal cortex - an action, which in positive circumstances is strongly associated with health and the development of meaning (Golembiewski, 2012). 
Fig. 48.17 Lean rails along corridor walls provide sufficient support for many residents to walk independently (top); as do walks on public streets, accompanied by care partners, friends, or family members (bottom). (Photographs (C) J. Zeisel 2005. Published with permission. All rights reserved)
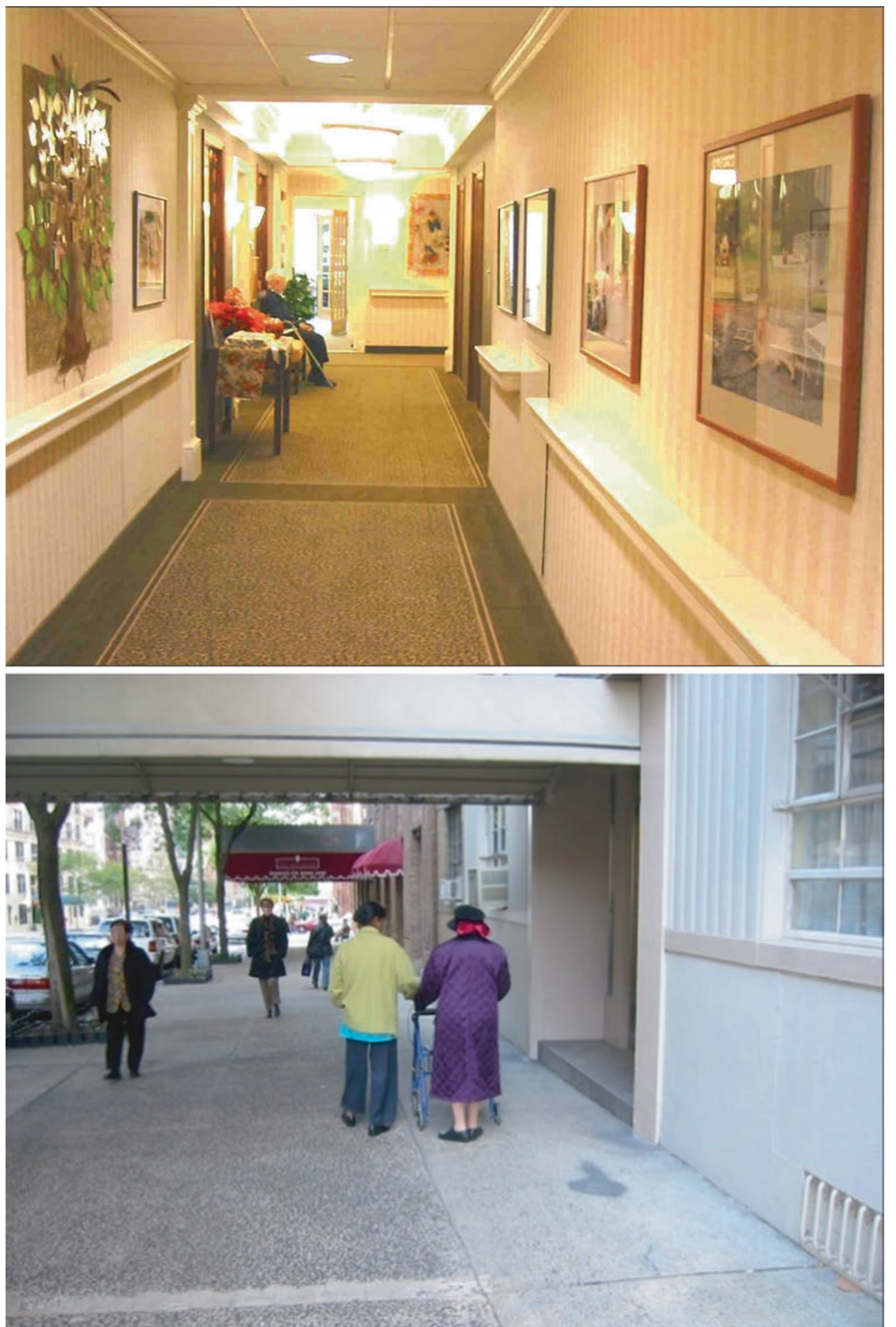

Providing options as to what a person can to do in a residence for PLWD is well within the control of such a residence - and it is an excellent way to foster meaningfulness (Zeisel, 2009).

When elders have trouble sleeping as they often do, choices need to be offered 24 hours per day and be appropriate for the time of day or night. During the day, residents might be offered choices including gardening, cooking, or looking after pets. In the evening, they might choose to dance, watch a movie, or play music. Late at night, they might be offered the choice to watch movie trailers and decide tomorrow's movie programme or a restful activity like drawing. 


\section{How Improving the Comprehensibility SRR Supports Manageability and Meaningfulness}

Environmental innovations such as those described above aim specifically to support the comprehensibility SRR, perhaps the most critical SRR for dementia. But such interventions also support manageability and meaningfulness - the other SRRs. The freedom to move around purposefully, for example, translates as meaningfulness; PLWD empowerment, seen in selfdirected action, is a feature of manageability. Similarly, access to nature and the freedom to garden or enjoy birds and other animals also supports the meaningfulness SRR, not only because of our evolutionary relationship with nature (Wilson, 1984), but also because the stories we associate with such environments are difficult to perceive as pernicious (Golembiewski, 2017a). Caring for anything (even just for plants) generates meaning (Francis \& Murtha, 2021). Being a field of action, involvement with nature supports manageability. If the plants produce food as a result that PLWD can use themselves or give to visitors, the sense of meaning and manageability is richer still (Golembiewski, 2019).

Family and friendships are critical to meaningfulness; providing engaging affordances for visitors and family are therefore essential. If family and friends feel welcome and have something to do when they visit, the guilty feelings many already have will be reduced, visiting will be more pleasurable, and they may choose to show up more frequently (Golembiewski, 2017b).

With the prison-guard responsibility taken off care partners' shoulders, they can focus their attention on the person rather than on safety and security. This enriched relationship maximises available salutogenic resources, which in turn leads to more intimate and informed person-centred care. Care partners can truly treat PLWD less as 'patients' and more like the people they are.

The more comfortable and settled PLWD are, the less they exhibit the four 'A's of Alzheimer's - anxiety, agitation, aggression, and apathy. Not only does this reduce reactive behaviours, but it may also slow the progressive increase in such reactive behaviours.

In sum, a good place to begin employing salutogenic principles to reinforce the capacities and personhood of PLWD is to include these salutogenic principles and guidelines into environmental design and communications.

\section{Salutogenic Design for Treatment, Not Management}

A primary salutogenic goal of residential facilities is to treat the behaviours that are considered by white-coat medicine as 'symptoms'; to help residents help themselves and contribute to their quality of life. The pivot point lies in a positive approach, focused on how opportunities are offered and perceived: Are they given generously? Are they offered as choices? Are they presented with love, affection, and even drama? Are they associated with fond memories? Or are they presented as obligations obscured with risk-aversion?

Salutogenic healthcare design takes design's contribution to treatment with the same seriousness as safety and functional operational concerns. This point is clearly made in the 2020 Annual Report of Alzheimer's Disease International Design Dignity Dementia - which emphasises the role of salutogenesis in design for dementia and makes the important distinction between design goals, principles, approaches and design responses (Fleming et al., 2020).

To treat dementias using salutogenic principles means providing an abundance of appropriate and positive choices of things to do, 24 hours a day, gardens that are accessible and productive and so, too, kitchens and bathrooms. Institutions can do better than just being generically homely. A cluster of homes, rooms, or apartments might allow for shared facilities and activities like a steam room, a massage room, a cinema, restaurants instead of dining halls, multisensory rooms, and rooms for music and art - the kinds of things most houses do not have. They can also be far more considered (and research-driven) in bringing appropriate stimulus into bedrooms, dayrooms, courtyards, and other facilities that are offered.

To assess the salutogenic success of a place people living with dementia call home, the degree that the design reinvigorates self-efficacy, self-esteem, power, community activism, righteous anger, optimism, and sense of control over the future must be measured. These salutogenic goals require a commitment to each person's sense of purpose and a significant growth of understanding.

Environments make a real difference to healing outcomes with designers increasingly able to achieve this as they continue to learn about salutogenesis and the forces that underlie the salutogenic model. Residents deserve health support when living in residential care. Salutogenesis does this - it supports health. It also does so much more for PLWD, especially in an institutional setting. Salutogenic guidelines keep everyone concerned in lockstep to maximise residents' free will, happiness, and sense of well-being, while at the same time limiting the expression of reactive behaviours. Salutogenesis can be used broadly; not just as a tool for the design of residential homes, but also for designing psychosocial approaches and MOCs to enable people to manage themselves (as much as they can), to invest in residents' sense of agency (in salutogenic theory-comprehensibility) and, most importantly, to help PLWD develop and maintain a sense of meaningfulness. 


\section{Bibliography}

American Psychiatric Association. (2014). Posttraumatic stress disorder. In Diagnostic and statistical manual of mental disorders (5th ed.).

Antonovsky, A. (1979). Health, stress, and coping. Jossey-Bass.

Antonovsky, A. (1987). Unravelling the mystery of health: How people manage stress and stay well. Jossey-Bass.

Bargh, J. A., \& Chartrand, T. L. (1999). The unbearable automaticity of being. American Psychologist, 54(7), 462-479.

Bargh, J. A., \& Dijksterhuis, A. (2001). The perception-behavior expressway: Automatic effects of social perception on social behavior. Advances in Experimental Social Psychology, 33, 1-40. https:// doi.org/10.1016/S0065-2601(01)80003-4

Barker, R. G., \& Wright, H. F. (1954). The Midwest and its children; The psychological ecology of an American town. Row, Peterson \& Company.

Bossen, A. (2010). The importance of getting back to nature for people with dementia. Journal of Gerontological Nursing, 36(2), 17-22. https://doi.org/10.3928/00989134-20100111-01

Butler, R. N. (1975). Why survive?: Being old in America (1st ed.). Harper \& Row.

Clay, R. A. (2001). Green is good for you: Psychologists' research explains the mental and physical restoration we get from nature and has important implications for how we build our homes, work environments and cities. American Psychological Association, 32(4), 40.

de Beauvoir, S. (1972). The coming of age. Putnam.

de Wit, M. M., de Vries, S., van der Kamp, J., \& Withagen, R. (2017) Affordances and neuroscience: Steps towards a successful marriage. Neuroscience and Biobehavioral Reviews, 80, 622-629. https://doi org/10.1016/j.neubiorev.2017.07.008

Descartes, R. (1641 (tr. 1986)). Meditations on first philosophy: with selections from the Objections and Replies (J. Cottingham, Ed.). Cambridge University Press.

Diette, G. B., Lechtzin, N., Haponik, E., Devrotes, A., \& Rubin, H. R. (2003). Distraction therapy with nature sights and sounds reduces pain during flexible bronchoscopy: A complementary approach to routine analgesia. Chest, 123(3), 941-948.

Dijkstra, K. (2009). Understanding Healing Environments: Effects Of Physical Environmental Stimuli On Patients' Health And WellBeing. (PhD). Universiteit Twente, Twente, Netherlands.

Fleming, R., Zeisel, J., \& Bennett, K. (2020). Design dignity dementia: Dementia-related design and the built environment (Vol. I). Alzheimer's Disease International.

Francis, K., \& Murtha, S. (2021). The inclusion and efficacy of firstperson narrative in the design of long-term care homes. Architectural Science Review. https://doi.org/10.1080/00038628.2021.1917336.

Frankl, V. E. (1963). Man's search for meaning: An introduction to logotherapy. Pocket Books.

Gazzaniga, M. S. (1998). The mind's past. University of California Press.

Gibson, J. J. (1979). The ecological approach to visual perception. Houghton Mifflin Company.

Gnanasekaran, G. (2016). "Sundowning" as a biological phenomenon: Current understandings and future directions: An update. Aging Clinical and Experimental Research, 28, 383-392.

Golembiewski, J. (2010). Start making sense; Applying a salutogenic model to architectural design for psychiatric care. Facilities, 28(3/4), 100-117. https://doi.org/10.1108/02632771011023096

Golembiewski, J. (2012). Salutogenic design: The neural basis for health promoting environments. World Health Design Scientific Review, 5(4), 62-68.

Golembiewski, J. (2013a). Blind spot (mental health facilities). In K. Copeland (Ed.), Australian healthcare design: A critical review of the design and build of healthcare infrastructure in Australia (pp. 57-62). International Academy of Design and Health.

Golembiewski, J. (2013b). Determinism and desire: Some neurological processes in perceiving the design object. International Journal of Design in Society, 6(3), 23-36.

Golembiewski, J. (2014). Introducing the concept of reflexive and automatic violence: A function of aberrant perceptual inhibition. Archives of Psychiatry and Psychotherapy, 16(4), 5-13. https://doi. org/10.12740/app/33358

Golembiewski, J. (2015). Salutogenic architecture in health care settings. In G. Bauer \& M. Mittelmark (Eds.), Handbook of salutogenesis: Past, present and future (pp. 267-276). Springer.

Golembiewski, J. (2016). The designed environment and how it affects brain morphology and mental health. HERD, 9(2), 161-171. https:// doi.org/10.1177/1937586715609562

Golembiewski, J. (2017a). Architecture, the urban environment and severe psychosis. Part I: Aetiology. Journal of Urban Design and Mental Health, 2(1) Retrieved from http://www.urbandesignmentalhealth.com/journal2-psychosis.html

Golembiewski, J. (2017b). Salutogenics and residential care for people with dementia. Australian Journal of Dementia Care, 6(3), 25-28.

Golembiewski, J. (2019). Salutogenic retrofit for an Islamic dementia home. Australian Journal of Dementia Care, 8(2), 5-18.

Hartig, T., Mitchell, R., de Vries, S., \& Frumkin, H. (2014). Nature and health. Annual Review of Public Health, 35, 207-228. https://doi. org/10.1146/annurev-publhealth-032013-182443

Kaplan, R., \& Kaplan, S. (1989). The experience of nature: A psychological perspective. Cambridge University Press.

Kitwood, T. (1997). Dementia reconsidered: The person comes first. Open University Press.

Larsen, L. S. (1992). Nature as therapy: An assessment of schizophrenic patients' visual preferences for institutional outdoor environments (Masters of landscape architecture). University of Guelph.

Lhermitte, F. (1986). Human autonomy and the frontal lobes. Part II: Patient behavior in complex and social situations: The 'Environmental Dependency Syndrome'. Annals of Neurology, 19(4), 335-343. https://doi.org/10.1002/ana.410190405

Lynch, K. (1960). The image of the city. MIT Press.

Moen, P., Elder, G. H., Lüscher, K., \& Bronfenbrenner, U. (1995). Examining lives in context: Perspectives on the ecology of human development (1st ed.). American Psychological Association.

Perkins, N. (2013). Including patients, staff and visitors in the design of the psychiatric milieu: Notes from the field. Facilities, 31(9/10), 379-390. https://doi.org/10.1108/02632771311324945

Sapolsky, R. (2017). Behave: The biology of humans at their best and worst. Vintage.

Sloan Devlin, A., \& Arneill, A. B. (2003). Health Care Environments and Patient Outcomes: A Review of the Literature. Environment \& Behavior, 35(5), 665-694. https://doi.org/10.1177/0013916503255102.

The Royal Commission into Aged Care Quality and Safety. (2019). Interim report: Neglect.

Ulrich, R. S. (1984). View through a window may influence recovery from surgery. Science, 224(4647), 420-421.

Ulrich, R. S., \& Parsons, R. (1990). Influences on passive plants in individual well-being and health. Paper presented at the Proceedings of the National Symposium on the Role of Horticulture in the WellBeing and Social Development, Washington, DC.

Ulrich, R. S., \& Simons, R. F. (1986). Recovery from stress during exposure to everyday outdoor environments. In J. Wineman, R. Barnes, \& C. Zimring (Eds.), The costs of not knowing: Proceedings of the seventeenth annual conference of the environmental design research association (p. 115). Environmental Design Research Association.

Ulrich, R. S., Zimring, C., Zhu, X., DuBose, J., Seo, H., Choi, Y., Joseph, A. (2008). A review of the research literature on evidence- 
based healthcare design. Health Environments Research \& Design Journal, 1(3), 61-125.

Wilson, E. O. (1984). Biophilia: The human bond with other species. Harvard University Press.

Zeisel, J. (1999). Life-quality Alzheimer care in assisted living. In B. Schwarz \& R. Brent (Eds.), Aging, autonomy and architecture: Advances in assisted living (pp. 110-129). Johns Hopkins University Press.

Zeisel, J. (2000). Environmental design effects on Alzheimer symptoms in long term care residences. World Hospitals and Health Services, $36(3), 27-35$.

Zeisel, J. (2007). Creating a therapeutic garden that works for people living with Alzheimer's. Journal of Housing for the Elderly, 21(12), 13-33. https://doi.org/10.1300/J081v21n01_02

Zeisel, J. (2009). I'm still here: A breakthrough approach to understanding someone living with Alzheimer's. Avery.

Zeisel, J. (2013). Improving person-centered care through effective design. Generations: Journal of the American Society of Aging, $37(3), 45-52$.

Zeisel, J. (2020a). At home with growing older presents John Zeisel, 'Despair and Hope': Innovations in the design of care environments and care approaches for people living with dementia. Retrieved from www.athomewithgrowingold.com
Zeisel, J. (2020b). Reducing the 4 "A"s of Alzheimer's through the engagement replacement method. Paper presented at the Living Well with Alzheimer's Conference, Tennessee. www.alz.org/tn.

Zeisel, J., \& Raia, P. (2000). Nonpharmacological treatment for Alzheimer's disease: A mind-brain approach. American Journal of Alzheimer's Disease and Other Dementias, 15(6), 331-340. https:// doi.org/10.1177/153331750001500603

Zeisel, J., \& Tyson, M. (1999). Alzheimer's treatment gardens. In C. C. Marcus \& M. Barnes (Eds.), Healing gardens: Therapeutic benefits and design recommendations. Wiley \& Sons.

Zeisel, J., Hyde, J., \& Levkoff, S. (1994). Best practices: An Environment Behavior (EB) model for Alzheimer special care units. American Journal of Alzheimer's Care and Related Disorders and Research, 4, 21.

Zeisel, J., Silverstein, N. M., Hyde, J., Levkoff, S., Lawton, M. P., \& Holmes, W. (2003). Environmental correlates to behavioral health outcomes in Alzheimer's special care units. The Gerontologist, 43(5), 697-711.

Zeisel, J., Reisberg, B., Whitehouse, P., Woods, R., \& Verheul, A. (2016). Ecopsychosocial interventions in cognitive decline and dementia: A new terminology and a new paradigm. American Journal of Alzheimer's Disease \& Other Dementias ${ }^{\circledR}, 31(6), 502-507$.

Open Access This chapter is licensed under the terms of the Creative Commons Attribution 4.0 International License (http://creativecommons. org/licenses/by/4.0/), which permits use, sharing, adaptation, distribution and reproduction in any medium or format, as long as you give appropriate credit to the original author(s) and the source, provide a link to the Creative Commons license and indicate if changes were made.

The images or other third party material in this chapter are included in the chapter's Creative Commons license, unless indicated otherwise in a credit line to the material. If material is not included in the chapter's Creative Commons license and your intended use is not permitted by statutory regulation or exceeds the permitted use, you will need to obtain permission directly from the copyright holder. 